University of Massachusetts Amherst

ScholarWorks@UMass Amherst

Masters Theses

Dissertations and Theses

July 2015

\title{
Experimental Test of Genetic Rescue in Isolated Populations of Brook Trout
}

Zachary L. Robinson

University of Massachusetts Amherst

Follow this and additional works at: https://scholarworks.umass.edu/masters_theses_2

Part of the Genetics Commons, Natural Resources and Conservation Commons, and the Population Biology Commons

\section{Recommended Citation}

Robinson, Zachary L., "Experimental Test of Genetic Rescue in Isolated Populations of Brook Trout" (2015). Masters Theses. 241.

https://doi.org/10.7275/7127259 https://scholarworks.umass.edu/masters_theses_2/241

This Open Access Thesis is brought to you for free and open access by the Dissertations and Theses at ScholarWorks@UMass Amherst. It has been accepted for inclusion in Masters Theses by an authorized administrator of ScholarWorks@UMass Amherst. For more information, please contact scholarworks@library.umass.edu. 


\title{
EXPERIMENTAL TEST OF GENETIC RESCUE IN ISOLATED POPULATIONS OF BROOK TROUT
}

\author{
A Thesis Presented \\ by \\ ZACHARY L. ROBINSON \\ Submitted to the Graduate School of the \\ University of Massachusetts Amherst in partial fulfillment \\ of the requirements for the degree of \\ MASTER OF SCIENCE
}

May 2015

Environmental Conservation 


\section{EXPERIMENTAL TEST OF GENETIC RESCUE IN ISOLATED POPULATIONS OF BROOK TROUT}

A Thesis Presented

by

ZACHARY L. ROBINSON

Approved as to style and content by:

Andrew Whiteley, Chair

Keith Nislow, Member

Ben Letcher, Consulting Member

Mark Hudy, Outside Member

Curt Griffin, Department Head

Environmental Conservation 


\section{DEDICATION}

To my parents who have worked tirelessly to give me the best opportunities, and have been an endless source of support. 


\section{ACKNOWLEDGEMENTS}

I would like to send a special thanks to my undergraduate and graduate advisors: A. Whiteley and M. Hudy. I thank you both for all of the opportunities that you have provided me with, and your continued support and guidance in launching my career as a young scientist. I would like to thank my other committee members for their support, guidance, and criticisms that helped guide this research.

Genetic Analysis

For conducting the genetic analysis I would like to thank M. Burak and M. Page for most of the foundational lab work for this project. I would like to thank all my undergraduate technicians $\mathrm{K}$. Pollard, M. Gillis, K. Buckley, and L. Miller.

Field work

I would like to thank C. Anderson, K. Cooney, J. Courtwright, P. Damkot, A. Ells, A. Fitzgerald, E. Joseph, M. Hickey, C. Kyger, H. Mohn, R. Sanders, A. Scire, B. Stanley, K. Tomlinson, B. Trumbo, and Forest Service CATT crew technicians that helped with field collections.

Organizational Support

Thanks to those who provided financial assistance or volunteer support: James Madison University, George Washington and Jefferson National Forests; Virginia Department of Game and Inland Fisheries; US Forest Service, Northern Research Station; University of Massachusetts Amherst; US Geological Survey, Leetown Science Center and Conte Anadromous Fish Research Laboratory. 


\begin{abstract}
EXPERIMENTAL TEST OF GENETIC RESCUE IN ISOLATED POPULATIONS OF BROOK

TROUT
\end{abstract}

MAY 2015

\title{
ZACHARY L. ROBINSON, B.S., JAMES MADISON UNIVERSITY
}

\section{M.S., UNIVERSITY OF MASSACHUSETTS AMHERST}

Directed by: Dr. Andrew Whiteley

Translocations are an important aspect of the management of natural populations in an increasingly fragmented landscape. Maintaining connectivity and gene flow is beneficial for both contemporary fitness and adaptive potential in the face of environmental change. Genetic rescue (GR) can alleviate inbreeding depression, genetic load, and increase adaptive potential of populations. Here, I have translocated 10 (5 of each sex) brook trout (Salvelinus fontinalis) to four geographically proximate and environmentally similar fragmented stream-dwelling populations of brook trout in Virginia to test for genetic rescue. The translocated brook trout contributed to more families than would be expected under neutral introgression, and hybridization resulted consistently in larger full-sibling family sizes. In the cohort immediately following translocation I observed relatively high ( $>20 \%)$ introgression in 3 of the 4 recipient sites, and in one recipient population $57.7 \%$ of the offspring had at least one migrant parent. During the post-translocation period favorable regional climatic conditions resulted in large cohorts across recipient sites and controls, however the percent increase in juvenile abundance scales to initial genetic diversity and patch size. I observe strong evidence of hybrid vigor through 
consistently larger body sizes of hybrid offspring. At this point I cannot rule out potential negative effects of translocations such as outbreeding depression with out sampling more cohorts following genetic recombination. However, I provide an empirical and replicated foundation to begin assessing the efficacy of GR-motivated translocations for headwater fish conservation, and make a substantial contribution to the growing body of GR-literature. 


\section{TABLE OF CONTENTS}

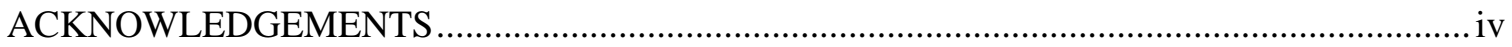

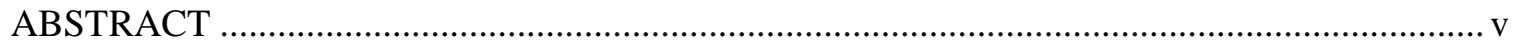

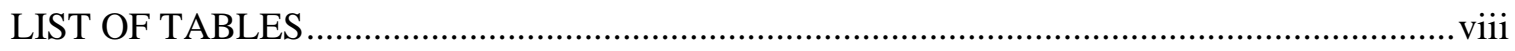

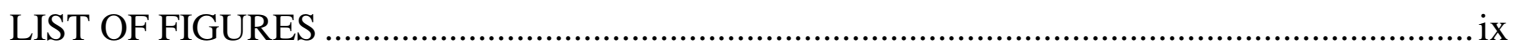

\section{CHAPTER}

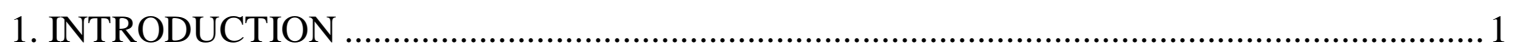

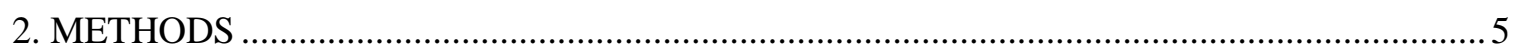

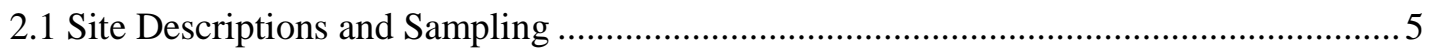

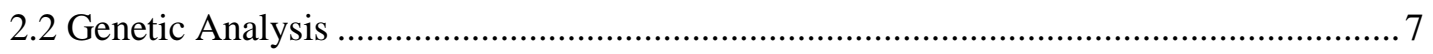

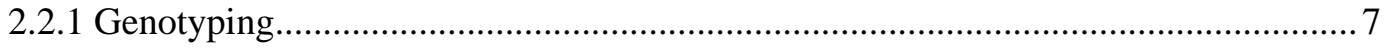

2.2.2 General Genetic Summary of the 2012 Cohort...................................................... 8

2.2.3 Pedigree Reconstruction .............................................................................. 9

2.2.4 Testing for Hatchery Introgression .............................................................. 11

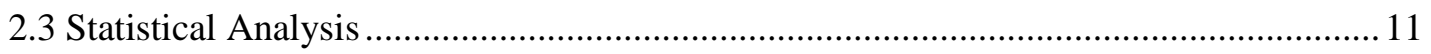

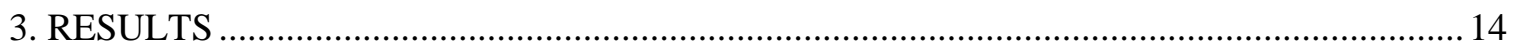

3.1 Demographic and Genetic Summaries .................................................................. 14

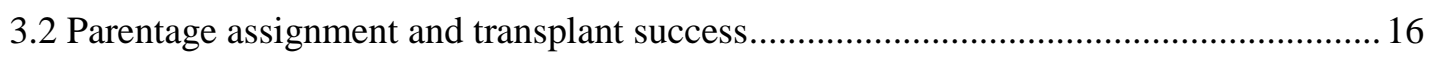

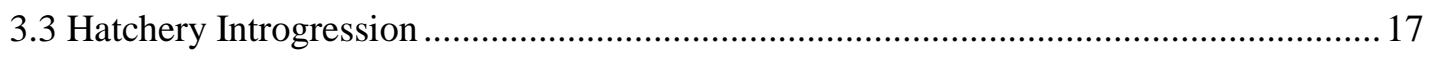

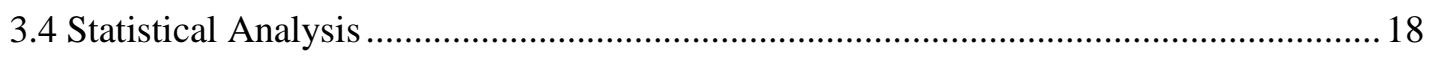

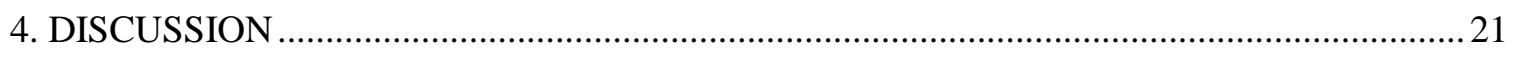

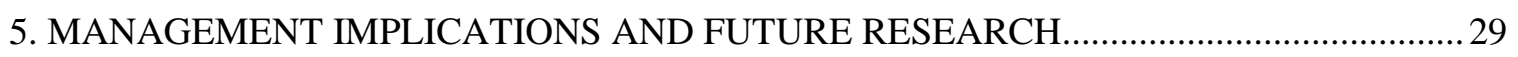

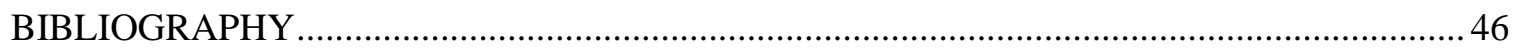




\section{LIST OF TABLES}

Table

1. Habitat and demographic summary of six brook trout habitat patches by sample year. 31

2. Genetic summary statistics of brook trout cohorts (young-of-year [YOY]) from six habitat patches and Coursey Springs hatchery.

3. Percent change of demographic and genetic summary statistics following translocation...... .33

4. Results of randomization tests of neutral introgression of transplanted brook trout at the family level in the $2012 F_{1}$ cohort. .33

5. Summary of observed reproduction and parentage assignment efficacy in each recipient population in the $2012 \mathrm{~F} 1$ cohort by lineage.

6. Transplant reproductive success, dispersal, and offspring body size by sex. .34

7. Correlations of habitat and genetic metrics to observed percent demographic change after translocations in recipient sites.

8. AICc model comparison of negative binomial family generalized linear models predicting fullsibling family size. 36

9. AICc model comparison of linear mixed models predicting $2012 \mathrm{~F}_{1}$ Cohort individual body size.

10. Two-sample tests of total length, family size (FS), and family dispersal by lineage class at the family level. 


\section{LIST OF FIGURES}

Figure Page

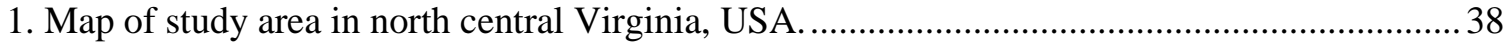

2. Length frequency histograms of brook by site and sample year. ............................................ 39

3. Histograms of full-sibling family size (FS) by site. 2011 FS distribution (left) and 2012 FS

distribution (right) as reconstructed by program Colony.................................................... 40

4. Within-stream family centroid locations of transplant produced families................................. 41

5. In stream distribution of young of year brook trout across sites and sample year.....................42

6. Mean and 95\% confidence intervals of total individual length (TL; nearest millimeter) by

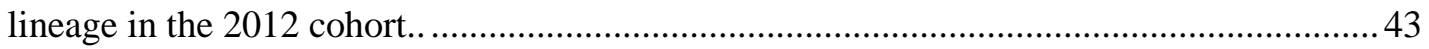

7. Summary of STRUCTURE results for hatchery and DV-b brook trout................................... 44

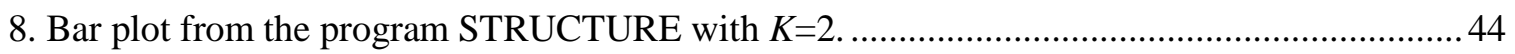

9. Comparison of fecundity of simulated female brook trout with observed transplant-resident

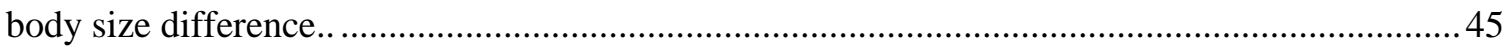




\section{CHAPTER 1}

\section{INTRODUCTION}

Native brook trout (Salvelinus fontinalis) are highly fragmented throughout their range due to numerous anthropogenic landscape changes. A study of sub-watersheds representing 70\% of the brook trout native range in the eastern United States found that $28 \%$ of historically documented populations are currently extirpated. Southern populations, south of the state of New York State, often occur in small isolated headwater streams (Hudy et al. 2008). Widespread stream fragmentation (e.g. dams, thermal unsuitability, hanging culverts) enable habitat to be discretely defined into occupied and connected hydrologic catchments that are dissolved into watersheds or "patches” of brook trout habitat (Whiteley et al. 2014). Of over 2800 delineated patches from Pennsylvania to Georgia the median size was 855 hectares with very few large contiguous patches remaining (Whiteley et al. 2014). A brook trout habitat patch most often represents a single population or in the case of large patches a metapopulation of brook trout (A. Whiteley, unpublished results). Patches are assumed to be demographically and genetically independent from one another, and are therefore important management units.

I expect small habitat patches to support small populations and likely experience greater demographic stochasticity (Lande 1993). The synergistic effects of genetic erosion, and small populations size (termed an extinction vortex) have been shown in both laboratory and natural populations to reduce probability of population persistence (Newman \& Pilson 1997; Palomares et al. 2012). For salmonid species, a decrease in the probability of persistence has been documented with the loss of contiguous habitat and decrease in patch size (Dunham et al. 1997; Harig \& Fausch 2002; Dunham et al. 2008). There is also strong evidence for above-barrier habitat patch size positively correlating with genetic diversity, and effective population size $\left(\mathrm{N}_{\mathrm{e}}\right)$ (Whiteley et al. 2010; Peacock \& Dochtermann 2012).

The importance of connectivity to stream-dwelling salmonids is further illustrated by their high spatial structure and metapopulation dynamics. Loss of connectivity under a source- 
sink metapopulation structure has been shown to drastically reduce the probability of persistence of salmonids populations (Koizumi 2011). Adaptive life history strategies such as early maturation have been observed to increase persistence probability within naturally fragmented (e.g. waterfalls) brook trout habitats (Letcher et al. 2007). Unfortunately, fragmentation is not the only strong anthropogenically induced selective force facing brook trout. Climate change, deforestation, and invasive species have also influenced range-wide decline (Hudy et al. 2008). Climate change is projected to have dramatic consequences for brook trout by an increase in summer stream temperatures beyond their physiological optima, and will be especially pronounced in the southern extent of their range (Trumbo et al. 2014). In addition, climate change is projected to increase the frequency of extreme events (e.g. flood, fire), but also increase competition with invasive species (Wenger et al. 2011). In order for populations to adapt to fragmentation and other concomitant stressors there must be sufficient standing genetic variation for selection to act upon. Furthermore, the available habitat must accommodate a large enough population for selection to overcome genetic drift.

In response to anthropogenic barriers that disrupt metapopulation connectivity (e.g. culverts, dams), translocations are becoming more widely considered in headwater fish conservation (Whiteley et al. 2013). This is based on the prediction that many isolated abovebarrier habitat patches are likely too small to preserve adequate abundance consistently for selection to overcome genetic drift. Reduced adaptive potential will lower persistence probabilities over conservation-relevant time frames. Functioning metapopulation dynamics can potentially protect these small local salmonid populations from extirpation (Letcher et al. 2007; Koizumi 2011), or provide individuals for recolonization following extreme events (Roghair \& Dolloff 2005).

The successful alleviation of detrimental inbreeding effects in isolated and small population size from gene flow, naturally or anthropogenically induced is referred to as genetic rescue (GR). GR has been defined as an increase in population fitness, greater than can be 
allocated to demographic contribution of immigrants, due to the immigration of new alleles (Tallmon et al. 2004; Whiteley et al. 2015). Population fitness under the most rigid criteria for GR is inferred by an increase in population size (mean absolute fitness) over multiple generations. More commonly, other individual-based fitness traits that assess mean relative fitness are used to illustrate the advantage of descendants that carry migrant alleles. The benefit of gene flow to isolated populations has been widely documented in a variety of taxa, and at low levels of immigration in laboratory and natural populations (Westemeier et al. 1998; Madsen et al. 1999; Newman \& Tallmon 2001; Miller et al. 2012).

There remains substantial concern in the scientific community about the risk of translocations and the possibility of inducing outbreeding depression (OD), while attempting to alleviate inbreeding depression (ID). OD is the reduction of population fitness due to immigration of new alleles disrupting local adaptation, epistatic gene interactions, or other intrinsic incompatibilities (Allendorf \& Luikart 2007). A common critique of GR literature to date is the lack of studies with replication and experimental controls on natural populations, which also adequately addresses potential adverse effects associated with OD (Tallmon et al. 2004; Whiteley et al. 2015). There has been an emergence of guidelines and decision frameworks to avoid OD when considering translocations (Frankham et al. 2011; Weeks et al. 2011). It has been suggested that OD has been largely over-emphasized, is easily predicted, and when these decision frameworks are applied the existing body of literature demonstrates consistent benefits of gene flow (Frankham et al. 2011; Frankham 2015).

It has been suggested that GR should only be implemented when inbreeding depression has been empirically demonstrated in order to avoid OD (Edmands 2007), however this may not be realistic for many organisms of conservation concern. Unfortunately, many species including salmonids pose considerable difficultly in demonstrating ID in natural populations due to cryptic phenotypes that are difficult to link to fitness and environment. There are some exceptions; a study of hatchery-reared and wild-released anadromous rainbow trout demonstrated $71 \%$ greater 
survival following a single inbreeding event in the non-inbred versus the inbred lines (Naish et al. 2013). It is not unreasonable to suspect that the economic costs of demonstrating ID could seriously obstruct the implementation of GR-motivated translocations. The reality of working with natural populations with experientially inconvenient generation lengths is that we will have to apply our knowledge of theoretical conservation genetics to take conservation action in absence of comprehensive information. Given the power of GR as conservation tool, and the current global biodiversity crisis we will increasingly need to carve out an area between overly cautious and overly risky approaches.

As addressed in Whiteley et al. (2013), the above-barrier populations examined herein have among the fasted documented losses in genetic diversity in short isolated ( $\sim 50$ years) salmonid populations. It is hard to imagine that these rapid losses in genetic diversity did not encumber fitness consequences along the way. In the absence of direct evidence of ID, we have a breadth of theory describing the conditions that are fertile to ID. Those criteria are certainly met in patchy, isolated, small, and environmentally stochastic brook trout populations. I expect deleterious stochastic processes to have a predominant influence, and overwhelm deterministic processes such as natural selection. Due to the fact that many, if not most, brook trout patches in the southern extent of their range meet these criteria these habitats may not persist or suffer reduce fitness without intervention. Artificially providing the metapopulation services of gene flow and recolonization may be critical for many isolated above-barrier brook trout populations. 


\section{CHAPTER 2}

\section{METHODS}

\subsection{Site Descriptions and Sampling}

This study includes six brook trout habitat patches in Rockingham and Augusta County of Virginia in the North River watershed, in the Potomac River basin. The six patches occur in three sub-watersheds. Dry Run (DN-a), Skidmore fork of Dry River (DV-a), and Dry River (DVb) all occur within the Dry River subwatershed. Little River (LR-a) and Skidmore Fork of North River (SF-a) both occur with in the Little River subwatershed. Briery Branch (BB-a) occurs in the Briery Branch subwatershed (Figure. 1). Five of the streams have been fragmented due to flood control dams (-a suffix on the site abbreviation denotes above a dam), which were constructed from 1962 to 1970 (Table 1). The habitat patch area was calculated in Whiteley et al. (2013), and defined as the area of contiguous catchments (seventh level, 14 digit hydrologic unit codes) of occupied brook trout habitat. Patch areas in the above-barrier patches range from $993-4,121$ ha

(Table 1). Stream lengths in the above-barrier patches range from 5.1 ha to 27.4 ha (Table 1). The source population for transplanted brook trout was DV-b. DV-b is considerably larger habitat than the five above-barrier sites with a patch area of 10,880 ha, and a stream length of $40.0 \mathrm{~km}$. The downstream extent of brook trout habitat in DV-b is thermally limited, presumably with major influences from land use practices (e.g. agriculture and deforestation).

\subsection{Brook Trout Sampling and Translocations}

Brook trout sampling consisted of exhaustive single-pass electrofishing surveys of entire habitat patch for DN-a, SF-a, and BB-a during July-August 2010, 2011, 2012, and 2013. DV-a was exhaustively sampled with single-pass electrofishing surveys in July-August 2010 and 2011, and then was subsampled due to time constraints in 2012 and 2013. LR-a was exhaustively sampled with single-pass electrofishing surveys in July-August 2010, 2011, and 2012; time constraints only allowed for a subsample to be collected in 2013. DV-b was sampled with 
electrofishing surveys from a single starting location below Switzer Dam (which isolates DV-a) for age-0 fish during September 2010, and for all size classes in October 2011 while acquiring potential transplants. Upon capture, individual length (nearest mm, total length (TL)) and location (nearest upstream meter from barrier-if applicable) were recorded, and a tissue sample (caudal fin clip) was taken as a source of genetic material and to serve as a mark for mark-recapture purposes.

Sampling during late summer allowed age-0 brook trout to become large enough to be captured efficiently while still enabling year-class differentiation based upon length (Hudy et al. 2000). I constructed length-frequency histograms for each patch and sample year to differentiate age-0 fish from over-yearlings. The empirical length frequency histograms have been shown to be strongly bimodal and age-0 fish were easily distinguished from over-yearlings (Whiteley et al. 2013). Each exhaustively sampled patch was resampled within two and four weeks of the initial capture event to estimate the proportion of marked to unmarked fish and abundance was estimated with the Lincoln-Petersen estimator (Otis et al. 1978).

Subsamples of LR-a and DV-a were conducted with three major objectives; 1) obtain densities in previously sampled sections, 2) obtain an estimate of detection probability, and 3) sample at least 25 age-0 fish from each third of the occupied stream length as prescribed by Whiteley et al. (2012) for estimating the effective number of breeders $\left(N_{\mathrm{b}}\right)$. A course index of abundance was generated from the subsamples by estimating a hypothetical exhaustive event for that year and multiplying by a probability of detection. First, I calculated the ratio of individuals in the subsampled reach to the number of individuals in that reach in exhaustively sampled years. The average number of encountered individuals in an exhaustive sample was then multiplied by the ratio of reach abundances to give a hypothetical exhaustive sample. The probability of detection estimated from the subsample, from either 3-pass depletions or mark-recapture, is then multiplied by the hypothetical first event of the subsampled year to give a point estimate of 
abundance. I conducted population estimates on both age- 0 and adults separately to accommodate unequal detection probabilities of age classes for both methods.

Translocations were conducted in October of 2011. The source of translocated individuals was DV-b (Figure 1). Ten brook trout consisting of five males and five females over 145 mm (TL) were translocated to four recipient patches: DN-a, BB-a, LR-a, and SF-a (Figure 1). Subsequently, five males and five females were removed from each recipient stream to control for demographic contribution of translocated fish. Due to the lack of a reliable sex marker for these brook trout populations, sex was determined from physiological differences apparent in the field (e.g. expressing milt, gravid females with swollen abdomen, and head shape). Twenty of the removed fish were euthanized, and the sexed after dissection. The fish were sexed correctly prior to dissection $100 \%$ of the time. The above-barrier patch DV-a did not receive translocated individuals and serves as a control for this study.

\subsection{Genetic Analysis}

\subsubsection{Genotyping}

All individuals for all populations were genotyped at eight microsatellite loci (SfoC113, SfoD75, SfoC88, SfoD100, SfoC115, SfoC129, SfoC24; (King et al. 2012), and SsaD237 (King et al. 2005) following protocols for DNA extraction and amplification detailed in King et al. (2005). PCR product was electrophoresed on either an ABI Prism 3100-Avant or an ABI Prism 3130xl genetic analyzer (Applied Biosystems Inc., Foster City, California), and hand-scored using Geneious version 7.1.2 (Biomatters Ltd., Available from http://www.geneious.com/). All samples obtained in the 2012 (post-translocation) cohort were genotyped in BB-a, SF-a, and DNa. Some analyses were limited to these three sites, and these are referred to as the core recipient sites. In LR-a due to the unexpectedly large number of brook trout captured I took a stratified random sample of 544 age-0 fish from three in-stream locations for genotyping (Whiteley et al. 2012) 


\subsubsection{General Genetic Summary of the 2012 Cohort}

Using the statistical computing program R version 3.1.0 (R Development Core Team 2014) I tested for Hardy-Weinberg (HW) proportions with the R package 'HWxtest' (Engels 2014). I used GENEPOP version 4.0.10 (Rouseset 2008) to test for linkage disequilibrium (LD). For both LD and HW I used sequential Bonferroni correction at an alpha $(\alpha)$ of 0.05 to correct for inflated type I error rates due to multiple testing (Rice 1989). I used the R package 'hierfstat' (Goudet 2014) to estimate allele frequencies, mean observed $\left(\mathrm{H}_{\mathrm{O}}\right)$ and expected $\left(\mathrm{H}_{\mathrm{s}}\right)$ heterozygosity, mean number of alleles $\left(\mathrm{A}_{\mathrm{O}}\right)$, and allelic richness (AR; mean number of alleles scaled to smallest sample size). A thorough evaluation of these populations with HW tests, LD tests, and examination for potential population substructure was conducted in Whiteley et al. (2013). Family structure within single-cohort samples can cause deviations from HW expectations, elevated LD, and bias estimates of genetic differentiation (Allendorf \& Phelps 1981; Anderson \& Dunham 2008; Rodriguez-Ramilo \& Wang 2012). Whiteley et al. (2013) found that family structure accounted for most violations in HW and LD for these loci in these populations, and that there was little evidence to suggest these loci violate expectations of neutral inheritance. Within patch population substructure was also evaluated for these sites using the program STRUCTURE version 2.3.1 (Pritchard et al. 2000) with support for $K=1$ in all cases. I reconstructed full sibling families within each population for the 2012 cohort using COLONY version 1.2 (Wang 2004). To minimize biases associated with family structure, I took a random sample of one individual per family to create a data set that was free of family structure (Rodriguez-Ramilo and Wang 2012). I reran the analyses outlined above for HW and LD, and recalculated genetic variation statistics with the random subset for each population. Mean fullsibling family size (FS) was calculated as $\mu$ from a fitted negative binomial distribution using the R package MASS (Venables \& Ripley 2002). I summarized the distribution of FS by calculating family evenness (FE) for each cohort as conducted in Whiteley et al. (2013). FE is the application of Pielou's J, originally defined for species data, to full-sibling families (Pielou 1975). $F E$ was 
calculated as $F E=\frac{H^{\prime}}{H^{\prime} \text { Max }}$, where $H^{\prime}=-\sum_{1}^{S} p_{i} \ln \left(p_{i}\right)$ and ${H^{\prime}}_{\text {Max }}=\ln (S)$. S, which usually represents the number of species in an evenness calculation, here represented the number of families and $p_{i}$ represented the proportion comprised of the $i^{\text {th }}$ family. I used Meirmans and Hedrick's unbiased estimator G’' ${ }_{\text {sт }}$ (Meirmans and Hedrick 2011) for estimates of overall and

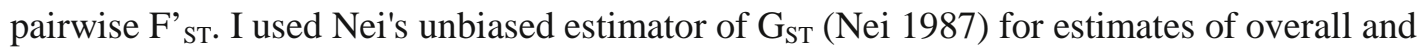
pairwise $F_{\text {ST. }}$ Both F' sт and $F_{\text {ST }}$ were calculated with the R package 'mmod’ (Winter 2012).

I estimated $N_{b}$ within each population and sample year. I used single sample gametic disequilibrium based estimates of effective population size $N_{\mathrm{e}}$ with in the program LDNe version 1.31 (Waples \& Do 2008). When this estimator is applied to a single brook trout cohort it is an estimate of $N_{b}$, or the number of effective breeders giving rise to that cohort. Within LDNe I assumed a monogamous mating model based on the report that $80 \%$ of mature headwater streamdwelling brook trout that contribute to a cohort produce a single family (Coombs 2010). I used a minimum allele frequency cutoff $\left(P_{\text {crit }}\right)$ of 0.02 ; this threshold has been shown to provide a balance between precision and bias across sample sizes (Waples \& Do 2008). I used a jackknife approach to produce 95\% confidence intervals around the point estimate of $N_{b}$ (Waples \& Do 2010). The magnitude of $N_{b}$, as estimated by LDNe, is predominately influenced by recent cohort-specific effects such as variance of FS (FE), the number of families produced, and familydependent survival prior to sampling with low bias associated with legacy effects of generational $N_{\text {e }}$ (Waples et al. 2014; Whiteley et al., In press) .

\subsubsection{Pedigree Reconstruction}

I conducted parentage assignment of each individual using PEDAPP version 1.1 (Almudevar 2007). The potential parents considered were all unique brook trout genotypes from 2010, 2011, and adults only in 2012 for each site. I then used PedAgree version 1 (Coombs et al. 2010) for sibship constrained (SC) parentage assignment using the PEDAPP parentage assignments and the full-sibling family output from Colony version 1.2. Simulations of 
microsatellite data sets have shown high accuracies when using Colony, PEDAPP, and PedAgree programs in conjunction (Coombs et al., In prep). The SC method was run using a minimum threshold value of 0.2501 for full-sibling families with two members, and 0.1667 for full-sibling families with three or more members (Letcher et al. 2011). Individuals in recipient patches that are assigned at least one transplant parent were considered to be resident-by-transplant first filial $\left(\mathrm{F}_{1}\right)$ cross type (RT). Similarly, offspring assigned two transplant parents were considered to be transplant-by-transplant $\mathrm{F}_{1}$ cross type (TT). All other offspring will be assigned to be resident-byresident $\mathrm{F}_{1}$ cross type $(\mathrm{RR})$.

In order to verify the efficacy of this procedure, I calculated the number of diagnostic (unshared alleles between resident and transplant populations) in each family. I calculated the proportional successful parental assignment for each recipient site from the following equation: $P A=\frac{A}{2 \times N_{\text {off }}}$, where $A$ is total number of parental assignments and $N_{\text {off }}$ is the number of offspring considered (note: PA is not assignment accuracy).

Parental assignments were also used to generate a pseudo-mid-parent length (PmP) for each offspring, in order to produce a covariate that accounts for parental effects (e.g. fecundity and inheritance). First, offspring that were not assigned any parents, and those who were not assigned a parent from a 2011 capture (individual lengths from different years are incomparable in this context) were dropped from consideration. Secondly, offspring that had only one parent assignment were assigned that parent's length value for PmP, while those with two parents were assigned the average parental length as PmP.

To access whether transplant introgression was greater than expected under neutral assumptions I created a null distribution of family lineage classes (RR, RT, TT). This was accomplished by drawing a parent for each observed family at random from a binomial distribution where the probability of drawing a transplant as a parent was equivalent to their proportional representation in the potential breeding population. The second parent was not 
treated as independent of the first, therefore if the first parent was a transplanted fish then the probability of drawing a resident fish increased with the decrease in the proportional representation of transplants (self-incompatibility). I then estimated proportion of families in each lineage, repeating this procedure 1000 times. I did not apply any prior probability of repeat spawning, or sex specific assumptions. Therefore, this should be quite conservative and give a maximum amount of introgression under neutral assumptions.

\subsubsection{Testing for Hatchery Introgression}

The Virginia Department of Game and Inland Fisheries (VDGIF) stocks DV-b five times a year with hatchery-reared brook trout from Coursey Springs Fish Cultural Station in Warm Springs, VA (VDGIF 2014). I obtained 75 genetic samples from the hatchery source to test for introgression into DV-b. I ran the program STRUCTURE version 2.3.1 (Pritchard et al. 2000) including brook trout captured from DV-b in 2010 and 2011, and hatchery samples. The program was ran with 100000 replicates and 20000 burn in cycles under an admixture model.

STRUCTURE was parameterized to infer a separate Dirichlet parameter for degree of admixture $(\alpha)$ for each population. Ten replicate runs were conducted for each value of $K$ one through five. To compliment raw log-likelihood values from STRUCTURE, I will also use the R package 'pophelper' (Francis 2014) to implement the Evanno method for the selection of $K$ (Evanno et al. 2005). For age-0 fish captured in DV-b, I randomly sampled one individual per family to minimize bias due to family structure. The hatchery fish were sampled as adults and could be mixed age, a case were sibship analysis is generally inappropriate. However, I ran Colony to identify potential family structure within the hatchery sample and prevent potential bias.

\subsection{Statistical Analysis}

To determine if differences existed in full-sibling FS among lineages, I used a negative binomial family generalized linear model (GLM) with a log link function in R. A negative binomial error model was assumed due to the nature of full-sibling FS as over-dispersed count 
data and precedence for its use in other studies (e.g. Araki et al. 2007; Naish et al. 2013). I modeled FS as a function of lineage and PmP. I used AICc for model comparison for all combinations of predictors and a null model of a fitted negative binomial (Burnham \& Anderson 2002). A power analysis was conducted for each core site in which I simulated 1000 datasets of FS from a negative binomial distribution for the observed sample sizes and effect sizes within each lineage and site. I constructed a negative binomial family GLM with lineage as a single predictor of FS for each of the simulated datasets. Individual length for the 2012 cohort was modeled as a linear mixed model LMM using the R package 'Ime4' (Bates et al. 2014). Individual length was modeled as a function of lineage, PmP length, and full-sibling family membership as a random effect. Models were compared using the R package 'AICcmodavg' (Mazerolle 2013) for AICc model comparison.

I calculated a series of family summary statistic for the $2012 \mathrm{~F}_{1}$ cohort including mean individual size, median distance from barrier (family centroid), median absolute deviation (MAD) of distance (family dispersal), and full-sibling FS. The family centroid as the median location of the individuals of a given family is considered the inferred redd location (Hudy et al. 2010). I evaluated the assumption of Gaussian error distribution for all continuous variables using a Shapiro-Wilk test. I created a secondary lineage variable with two categories where I pooled the lineages for RT and TT to represent offspring with at least one transplant parent (T). I then tested for differences in central tendency between lineage categories R-T and RR-RT for mean individual size, family dispersal, and full-sibling FS using either Wilcoxon signed rank test or student's t-test. I conducted these comparisons for the minimum FS cutoffs of 1-5, to access sensitivity to small families that could produce outliers and otherwise influence analyses. Comparisons of TT are omitted due to underrepresentation at the full-sibling family level. These two-sample tests for full-sibling FS and individual length are intentionally redundant with the GLMs due to the data structure required for each type of analysis and subsequent loss of observations. 
I calculated the mean absolute distance of each of the transplant parent's family centroid to their release point in the stream, and will refer to this metric as release dispersal. I also calculated the pairwise distance of all family centroids belonging to a given migrant individual and refer to this metric as reproductive dispersal. I tested if there were differences among the sexes in dispersal using a Wilcoxon rank sum test. I also tested if transplants of a certain sex produced larger hybrid offspring, using a student’s t-test.

It was critical in models of FS and individual length that the potentially confounding effect of parental body size was accounted for through PmP. To further evaluate this potential bias, I explicitly tested if translocated brook trout were larger than residents. A randomization test was conducted for each site by taking samples of size 10 with replacement from 2011 adult resident fish and differenced from the translocated fish. Potential transplant individuals were obtained at an a priori specified length threshold of $145 \mathrm{~mm}$ and thus residents were sampled above this threshold. I repeated this procedure 1000 times to produce a distribution of mean differences. A Wilcoxon signed rank test was employed to test for differences in individual length between the removed resident fish and the supplemented transplants for each site independently.

I also generated simulated data in order to evaluate the extent to which translocations may have resulted in moving more eggs into the recipient populations by replacing resident females with larger translocated females. I simulated 1000 lengths from a random normal distribution with the mean and standard deviation of the average resident brook trout TL, I then randomly sampled 5 individuals in the range of $145 \mathrm{~mm}$ to $300 \mathrm{~mm}$ and calculated clutch size from the size-fecundity relationship published in Letcher et al. (2007). In order to produce simulated translocated brook trout to compare to residents I repeated this procedure increasing the mean by the observed resident-transplant mean difference. 


\section{CHAPTER 3}

\section{RESULTS}

\subsection{Demographic and Genetic Summaries}

I genotyped 3909 individual brook trout at eight microsatellite loci from five brook trout patches (Figure 1), in addition to the 2502 genotypes previously published in Whiteley et al. (2013) for these sites. Empirical length frequency histograms were highly bimodal as expected, and age-0 fish were distinguished from the age-1+ with length frequency histograms (Figure 2). Mean estimated adult census size $\left(N_{c}\right)$ was 498 (range 37-1982; Table 1). Mean abundance of age-0 brook trout ( $N_{\text {YoY }}$ ) was 1228, (range 30-4792; Table 1 ). Mean proportional representation of translocated brook trout in the adult population for the 2011-spawning season was 0.1034 (range 0.031-0.196; Table 4). The abundance of age-0 brook trout generated in the cohorts following the translocation were dramatically larger with a mean percent change of $\Delta N_{\text {YOY }}=$ $1057.6 \%$ (range 317.4\% - 2393.3\%) from 2011 to 2012 (Table 3). The large post-translocation cohorts of 2012 did successfully recruit to age-1. Large increases in adult population size were observed from 2011 to 2013 with a mean percent change of $\Delta N_{\mathrm{c}}=392.2$ (range $185.6-937.3 \%$ ) (Table 3). The total amount of occupied $50 \mathrm{~m}$ stream sections increased by $54.6 \%$ (range 10.0 $141.6 \%$ ) on average from 2011 to 2012 in recipient sites. The amount of occupied $50 \mathrm{~m}$ stream sections occupied by YOY increased by $88.0 \%$ (range 29.4 - $237.5 \%$ ) on average from 2011 to 2012 in recipient sites (Table 3). Using Kendall’s $\tau$, percent change in demography $\left(N_{\mathrm{C}}\right.$ and

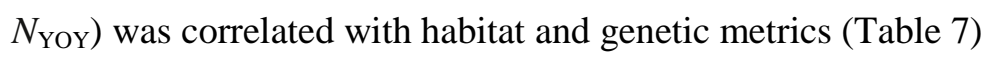

Mean $\mathrm{A}_{\mathrm{O}}$ per population and cohort was 7.8 (range 2.8-11.8), mean AR (standardized to $N=27$ ) was 6.3 (range 2.8 - 8.8), and mean $\mathrm{H}_{\mathrm{s}}$ was 0.68 (range 0.39 - 0.80) (Table 2). Mean reconstructed full-sibling FS was 4.472 (range 1.417 - 13.149), mean number of full-sibling families per population is 58.824 (range 12 - 145), and mean FE was 0.917 (range 0.834 - 0.975) (Table 2). The translocation of brook trout dramatically increased the genetic diversity of 
recipient populations in the following cohort. Percent change in genetic variation statistics following translocation were calculated as percent change from 2011cohort (pre-translocation) to the 2012 cohort (post-transplant). Mean percent $\Delta \mathrm{AR}$ (standardized to $N=27$ ) was $45.4 \%$ (range $14.0108 .2 \%$ ), and mean percent $\Delta \mathrm{H}_{\mathrm{s}}$ was $24.1 \%$ (range $2.5 \%$ - 65.7\%) (Table 3). The subset of the data that contained one randomly selected individual per family contained $N=1000$ individual brook trout genotypes, and the per site sample size is equivalent to the number of reconstructed families for a given site (Table 2). This subset of the data produced similar estimates of genetic variation within sites (Table 2). Mean AR (standardized to $N=12$ ) was 5.6 (range 2.6 - 7.1) and $\mathrm{H}_{\mathrm{S}}$ was 0.69 (range $0.40-0.80$ ) (Table 2).

There were 143 tests for departures from HW proportions. Prior to corrections for multiple tests 85 (63\%) were significant ( $\alpha=0.05$ ), with 7 significant tests predicted by chance. After applying sequential Bonferroni correction to each population with eight per locus tests the ( $\alpha=0.05$; initial nominal p-value was 0.00625$) 75$ (56\%) of significant tests remain. After reducing the influence of family structure by using the random subset of one individual per family there were 10 significant tests prior to correction for multiple test ( $\alpha=0.05$ ), with 7 expected by chance. After applying sequential Bonferroni correction to each population with eight per locus tests ( $\alpha=0.05$; initial nominal p-value was 0.00625 ) none of the significant tests remain. There were no apparent patterns across loci or populations for the significant departures from HW.

For the entire data set there were 469 tests for LD conducted, and prior to correction 340 (72\%) were significant at $(\alpha=0.05)$, with 23 significant tests predicted by chance. After sequential Bonferroni correction for 64 comparisons in each population 292 (62\%) of the tests remained significant at ( $\alpha=0.05$; initial nominal p-value was 0.00078$)$. Randomly selecting one individual greatly reduced the number of significant test for LD. Of the 463 tests with the random subset, prior to correction for multiple tests, 72 (16\%) of the tests were significant ( $\alpha=0.05$; with 23 predicted by chance). After sequential Bonferroni correction 10 tests remained significant at 
( $\alpha=0.05$; initial nominal p-value was 0.00078$)$. There were no apparent patterns for individual populations or among loci. As compared to the findings of Whiteley et al. 2013 I find an increase in significant tests of LD from 2 to 10 following sequential Bonferroni in the random subset data, with the additional eight all occurring in the 2012 cohorts in recipient sites.

The mean $\mathrm{N}_{\mathrm{b}}$ estimate was 60.188 (range 4.9 - 191.2). Overall, $\mathrm{N}_{\mathrm{b}}$ increased in recipient sites with a mean $\Delta \mathrm{N}_{\mathrm{b}}=10.0$ from the 2011 (pre-transplant) to 2012 (post-transplant) recipient cohorts, a modest increase in light of sampling 40.5 more full-sibling families on average (Table 2). The control site had a $\Delta \mathrm{N}_{\mathrm{b}}=91.2$ from the 2011 (pre-transplant) to 2012 (post-transplant), despite the fact that I sampled 79 fewer families than the year previous (Table 2). The $\mathrm{N}_{\mathrm{b}}$ confidence interval for DN-a 2011 included infinity and was not included in the summaries above (Table 2). This result was due to small sample size $(N=27)$, despite exhaustive sampling and low genetic diversity.

\subsection{Parentage assignment and transplant success}

The mean PA for recipient sites was 65.4\% (range 49.1 - $85.4 \%$ ) across all lineage classes (Table 4). The sibship-constrained parentage appears to have been accurate in classifying the lineage of each family. In recipient populations the mean number of diagnostic alleles per family in each lineage class are as follows $\mathrm{RR}=0.04$, $\mathrm{RT}=3.8$, and $\mathrm{TT}=7.4$ (Table 4). The rare occurrence of diagnostic alleles in the RR lineage class is due to the limited power of this parentage assignment process for small families, and in one instance it appears that a mutation produced a previously diagnostic allele in an individual of a resident family. The parentage assignment results revealed an experimental error in SF-a. A single family of size six was assigned two translocated field-assigned males (VaGT-1619 and VaGT-9340). Upon further review, VaGT-1619 fortuitously contributed to a second TT family of size one with a fieldassigned female VaGT-5663. The most parsimonious and empirically supported explanation for 
the observed families was that VaGT-9340 was a female mistakenly identified as a male in the field (Figure 4).

In the core recipient sites combined three of the male transplants and four of the female transplants were recaptured in 2012, with a mean recapture rate of $23.3 \%$ for these three sites. The fish that were recaptured exhibited a mean growth rate from 2011 to 2012 of $58.8 \mathrm{~mm}$ (range 48.3 - 75.0). I observed a mean introgression (proportion of alleles of migrant origin) in the core sites of $24.4 \%$ (range 20.8 -30.9 \%), and $4.8 \%$ in LR-a (note: LR-a was subsampled). All five female transplants produced offspring in BB-a and DN-a. Five of the six females reproduced in SF-a. Three of five males reproduced in BB-a and DN-a, while three of the four males reproduced in SF-a. In LR-a, although not comprehensively genotyped, I observed reproduction from four females and three males (Figure 4). In DN-a and SF-a transplant females produced 69.1\% and 66.4\% of T lineage offspring, respectively. In BB-a and LR-a transplant males produced 57.9\% and 67.3\%, respectively (Table 5). The RT hybrid lineage class consistently had larger family sizes across all populations. Mean full-sibling FS in each lineage was RR $=10.0, \mathrm{RT}=14.1 \mathrm{TT}=$ 13.0 across the core populations (Table 5). Results from the randomization test of neutral introgression revealed that there was consistently greater than expected RT families in all recipient sites, with significance $(\alpha=0.05$ ) in BB-a, DN-a, and SF-a (Table 4). The mean percentage of offspring in each lineage class in the 2012 core recipient site cohorts are $\mathrm{RR}=55.7$ $\%$, RT $=39.8 \%$, and TT $=4.5 \%$ (Table 5).

\subsection{Hatchery Introgression}

From 53 hatchery brook trout tissue samples I observed an AR $=4.8$ (standardized to $N=$ 27) and $H_{s}=0.71$ (Table 2). Prior to correction for multiple tests one of eight HW and two of 28 LD tests were significant. Following sequential Bonferroni correction only a single significant LD test remained, with no significant HW tests remaining. Despite power limitations of my marker panel; I observed minimal evidence for introgression of hatchery brook trout in the source 
of the transplants, DV-b. Genetic differentiation was relatively high with a mean pairwise $F_{s t}=$ 0.077 and an $F^{\prime}{ }_{s t}=0.55$ between all sample years of DV-b and hatchery samples. Further examination using the program STRUCTURE supported these results with $K=2$ being most supported by the Evanno method (Figure 7, Evanno et al. 2005), distinctly splitting the hatchery samples from DV-b (Figure 8). Mean proportional assignment of DV-b individuals to the hatchery cluster was $q=0.01$. The maximum proportional assignment to the hatchery cluster observed for a DV-b brook trout occurred in a juvenile from $2011 q=0.15$, which appears to be an outlier $(S D=6.6)$. There is less evidence for hatchery introgression into the translocated DV-b brook trout with a mean assignment to hatchery cluster of $q=0.0065$ (range $0.002-0.047$ ). All 90\% credible intervals of DV-b fish assignment to the hatchery cluster included zero.

\subsection{Statistical Analysis}

Model comparisons of negative binomial family GLMs with FS as the response and lineage and PmP as possible predictors were conducted in each site. The global model (including both PmP and lineage) was most supported in SF-a with the $\triangle \mathrm{AICc}=1.4$ to the second most supported model. In BB-a the model with PmP as the sole predictor was most supported, with a $\Delta \mathrm{AICc}=4.0$ to the second most supported model. The null model was most supported in $\mathrm{DN}-\mathrm{a}$, with a $\triangle \mathrm{AICc}=0.014$ to the second best model, including a single predictor PmP (Table 8). Including PmP improves the conceptual quality of these models, however, due to missing parent information for some full-sibling families, there is a loss of sample size of 30.5\% (range 22.5 $39.1 \%)$ on average. This constraint limited the power to detect a trend, if one indeed exists. A power analysis conducted for each population using the GLM with lineage as a single predictor (not including PmP and associated sample size loss) revealed that, given my observed FS effect sizes ( $\bar{x}=4.1$; range $2.4-5.6$ ) for RT families (the lineage class with greatest FS effect) and observed sample sizes, I would observe significance 36.3\% (range $8.2-63.3 \%$ ) of the time on average. 
The assumption of Gaussian error distribution for individual length was supported by a Shapiro-Wilk normality test for all 2012 cohorts. Model comparisons of LMMs with a global model of individual length ( $F_{1} 2012$ Cohort) as a response predicted by lineage, PmP, and family membership (random effect) were constructed in each population. I observed the models including lineage most supported in DN-a, SF-a, and plausible in BB-a (Table 9). For the t-tests of individual length ( $F_{1} 2012$ Cohort) at the full-sibling family level between the lineage classes RR-RT and R-T pooled classes for sites DN-a and SF-a produced significant results at all FS thresholds after sequential Bonferroni correction, with the transplant lineage classes being larger in body size (Table 10). In BB-a, eight of the ten t-tests for individual length were significant ( $\alpha=$ 0.05), with the transplant lineage classes being consistently larger in body size. The two that were not significant were the FS thresholds 2 and 3 in the R-T lineage comparison. Following sequential Bonferroni correction three significant tests of individual length remained in BB-a (Table 10). In LR-a, four of the ten t-tests were significant for individual length, they occurred at FS thresholds one and two in both R-T and RR-RT lineage classes. Following sequential Bonferroni correction two significant tests of individual length remained in LR-a (Table 10).

All other family level metrics were considered to be non-normally distributed, as supported by a Shapiro-Wilk normality test, and therefore two-sample test were conducted with a Wilcoxon signed-rank test. I found no significant differences at any FS threshold or lineage class category for family dispersal or FS in SF-a, LR-a, and BB-a. Interestingly, 8 of the 10 tests for family dispersal and FS were significant in DN-a at (alpha=0.05) with insignificant tests occurring at FS threshold of one, with larger FS and dispersal in transplant lineage classes. Following Bonferroni correction one significant FS test and 5 dispersal tests remained significant in DN-a (Table 10). I found no significant tests in reproductive dispersal or release dispersal between the sexes of transplant parents. I did, however, find that hybrids with female transplant parents were significant larger in DN-a than those sired by male transplants (Table 6). 
The randomization procedure testing for differences in individual length between 2011 adult residents and transplants yielded no significant results $(\alpha=0.05)$ for any site. The median difference across all populations was $-9.35 \mathrm{~mm}$ (Percentiles: $2.5^{\text {th }}=-32.6,97.5^{\text {th }}=15.4$ ) on average. The mean difference between the 10 residents removed from the population and the 10 that replaced them was on average $-9.6 \mathrm{~mm}$ (range -25.8 - 6.7). However, it was only found to be significant using a Wilcoxon rank-sum test in a single site, SF-a $(W=19, P=0.02)$. For the randomization test it is important to remember that transplants were captured in October 2011, while residents were captured two months earlier, therefore there is likely bias due to growth between times of capture. Furthermore, based on known body-size-fecundity relationships for brook trout, there is no reason to suspect that I moved in a biologically significant greater number of eggs when replacing five females with transplants from DV-b (Figure 8). 


\section{CHAPTER 4}

\section{DISCUSSION}

I found a dramatic amount of transplant reproduction in recipient sites, and more than would be expected under neutral assumptions (Table 4). This study serves both to encourage the potential success of moving a small number of individuals, and caution against overestimating the number of individuals required for a given target amount of gene flow. Prior to starting the study I did not have an explicit target amount of gene flow, as I did not know if I would observe any successful reproduction or what amount of mortality to expect from the translocation itself. The objective was to provide a pulse of gene flow, but to avoid genetically swamping recipient populations. I observed a maximum amount of introgression in DN-a of (30.9\%), but did not reach the proposed threshold for genetic swamping, where $\geq 50 \%$ of the alleles in the population are of immigrant origin (Frankham 2015). However, it should not be understated that the observed reproductive success of transplants surprised those involved in this project.

As addressed in Whiteley et al. (2013), these above-barrier recipient populations have among the fasted documented losses in genetic diversity in short isolated ( $\sim 50$ years) salmonid populations. The observation that the population (DN-a) that was the closest (geographically) to the source (DV-b) was the most genetically dissimilar is a testament to the force of stochastic genetic processes on these above-barrier populations (Whiteley et al. 2013). I observed substantial gains in genetic diversity in recipient sites. In my most genetically depauperate site, DN-a, AR more than doubled and $\mathrm{H}_{\mathrm{s}}$ increased by more than $50 \%$ in the 2012 cohort (Table 3). The reproductive success of these $\mathrm{F}_{1}$ cohorts in recipient sites, with the associated genetic recombination, will determine to what extent this pulse of gene flow will incorporate into these population's gene pools. It will require more study over multiple generations to access the lasting benefit (or detriment) of this gene flow event.

During the post-translocation period the study region experienced relatively benign conditions as compared to the drought conditions of 2010-2011. The observed increases in YOY 
abundance following translocations occurred across all recipient sites and the control. A recent study, conducted nearby in Virginia, USA, showed a remarkably strong influence of regional climatic patterns on local brook trout population fluctuations (Kanno et al. 2015). It is important to recognize that offspring produced in the $F_{1}$ post-translocation cohort likely did not experience the full scope and strength of selective pressures that exist in these sites. These benign conditions are further supported by dramatic increases in available habitat (occupied $50 \mathrm{~m}$ sections), particularly for YOY (Figure 5). Therefore, the relatively large 2012 cohorts should not be attributed directly to the translocation’s success in alleviating inbreeding depression.

With four replicates comparisons among sites should couched in the appropriate caveats of statistical power. However, it should not go unnoticed that the percent change in demography $\left(\mathrm{N}_{\text {YOY }}\right.$ and $\mathrm{N}_{\mathrm{c}}$ ) was most strongly correlated to initial genetic diversity rather than initial or percent increase in availability of habitat (Table 7). This relationship is driven by DN-a, because it contained lowest initial genetic diversity and the second smallest patch size. Patch size and genetic diversity have been demonstrated to be strongly correlated in these sites (Whiteley et al. 2013), and I predict that the smallest sites will have experienced the most genetic erosion. This provides some support for the ultimate qualification of GR, that is, linking the amount of initial inbreeding to demographic increase following the introduction of migrants. The inverse relationship of percent demographic change and initial genetic diversity suggests, as was predicted a priori, that reproductive capacity may have been limited by fragmentation-induced genetic erosion in these sites.

I observed a consistent pattern of larger mean family sizes in the hybrid lineage across sites (Table 5). Neither GLMs nor two-sample testing supported to this finding (Table 7; Table 9). However, a post-hoc power analysis revealed that these suffered from low power. In fact, the nature of FS as over dispersed count data makes statistically validating potentially biologically significant effect-sizes with realistic sample sizes quite difficult. Given that the year examined had relatively high reproductive output I should not expect to greatly increase sample size 
(sample more families), nor is it likely that effect sizes will increase in future cohorts. Although, FS is of great biological interest attempts to statistically validate patterns will suffer from low power when appropriate probability distribution (negative binomial, see Araki et al. 2007) or non-parametric approaches are applied.

I took great care to address concerns regarding the potential cause of the reproductive success of transplants, most importantly their body size. My analysis demonstrates that body-size dependent effects appear inadequate to explain the observed patterns in transplant reproductive success. There is no statistical evidence that transplants were dramatically larger than the resident population, and only in one site is there evidence that transplants were larger than removed residents; the biological significant of which can be debated. Assuming that there was a difference, I simulated data to estimate the potential impact on overall fecundity if transplants were $10 \mathrm{~mm}$ larger on average than residents. I contend that these differences are unlikely biologically significant at the population scale (Figure 8).

Other potential intrinsic migrant characteristics that could influence the observed reproductive pattern across lineages are life-history strategies. Strategies such as spawn timing, egg-size- versus clutch-size tradeoffs, and redd placement or structure may help explain the success of migrants. Also, the mere introduction of migrants close to fall spawning may have disrupted dominance hierarchies and potentially skewed reproductive success in favor of newcomers. Brook trout have been shown to have more complex dominant hierarchies than previously thought (White \& Gowan 2013), and these hierarchies likely play an important role in individual fitness (Hughes 1992). The stream flow intermittency of these patches results in high habitat heterogeneity and high fish densities, which lends credence to the potential importance on dominance hierarchies during spawning. These questions are beyond the scope and approach of this study, but should caution the reader against simply prescribing the reproductive success of transplants to purely genetic sources. 
I observed unimpressive increases or decline in recipient populations $\widehat{N}_{b}$ despite sampling nearly 2-fold increases in the number of families in the cohort following the translocation (Table 3). This is most likely attributed, as increase in significant LD tests support, to an increase in mixture LD following the introduction of divergent genomes from translocated brook trout (Table 2). Conservation practitioners should be cautioned against assessing demographic response using single cohort LD-based estimates of $N_{\mathrm{e}}$ following a migration event (natural or anthropogenic). This is expected due to admixture of divergent genomes elevating LD and causing heterozygote excess, this phenomenon has been experimentally shown to cause short-term spikes in LD in neutral markers, increasing both bias in LDNe- $\widehat{N}_{b}$ and the number of significant LD tests (Slate \& Pemberton 2007; Waples \& England 2011).

There was no evidence of hatchery introgression into source population despite intensive contemporary and historical stocking of hatchery-reared brook trout (VDGIF 2014). I conducted this analysis to attempt to address concerns that hatchery-sourced genetic material may have been moved into recipient populations. This would obviously be an undesirable management action, and be counterproductive to maintaining the genetic integrity of native brook trout. It would also be an unfortunate irony as many fisheries scientists, particularly in the western United States, are beginning to look somewhat favorably towards anthropogenic fragmentation insofar as it protects native populations from hybridization and competition with invasive species (Peterson et al. 2008; Fausch et al. 2009). The lack of evidence for hatchery introgression despite intensive stocking is not an entirely uncommon result (Fraser 2008; Annett et al. 2012). There are reasonable pre-zygotic and post-zygotic explanations for the observed lack of introgression. There has been well-documented low survival of hatchery fish, and substantial reductions in hybrid fitness that could result in negligible or non-existent reproductive success (Fraser 2008). There are some caveats to my approach, as I lacked historical pre-stocking reference samples, relied on one hatchery source (the state designated hatchery for this stream), and had power limitations due to the 8-microsatellite-marker panel used. 
Body size is correlated with key demographic processes in brook trout such as growth, survival, reproduction, and movement (Letcher et al. 2011). However, under certain conditions being large may not be advantageous, or otherwise represent a fitness trade-off between fecundity (correlating strongly with body size, especially for females) and survival. The selection regime on body size differs greatly across a multitude of temporal, spatial, and environmental gradients (Xu et al. 2010), thus making it difficult to infer the fitness benefit of a given body size. That said, body size has an indirect and dynamic, but intuitive link to fitness in brook trout. In the first year of life, body size may be more directly related to fitness, due to the influence of swimming ability on survival and resource acquisition (Tetzlaff et al. 2005; Nislow \& Armstrong 2012). The ability of a brook trout fry to generate rapid somatic growth is likely closely related to survival and thus fitness. It has been shown that brook trout can maintain their juvenile size differences throughout life, which may have further implications for dominance hierarchies, sexual selection, and resource competition (Letcher et al. 2011).

I found that hybrid individuals captured in 2012 were consistently larger across all recipient populations. This is supported both by the LMMs and rigorous two-sample testing. This appears to be hybrid vigor. That is, the synergy of genetic characteristics of transplants and residents resulting in above average somatic growth to the juvenile stage. From a mechanistic perspective this effect is unlikely the direct heritability of body size. Alternatively, it could be the result of fitness characters associated with metabolic efficiency, and perhaps behaviors that avoid high-energy expenditure and increase food-resource acquisition. However, alternative and nongenetic explanations should not be entirely ruled out and are not mutually exclusive. The time of spawning, timing of emergence, redd placement, and egg-size differences could produce substantial length differences at the time of sampling (Letcher et al. 2011).

Explanations of offspring body size differences based on emergence and redd placement are beyond this scope of this study, but I do not observe any evidence for spawn timing differences or egg-size differences. If there were dramatic differences in spawn timing I would 
expect some effect of mismatching. In fact, I actually see greater than expected production of hybrid families, which demonstrates that there must have been substantial overlap of spawning period. I would also expect this mismatch to affect transplant females disproportionately through delayed or accelerated spawning (Gaudemar \& Beall 1998; Berejikian et al. 2000). I observe the opposite pattern in the two smallest patches (DN-a and SF-a), where females dramatically outperform male reproduction (Table 6). If the observed patterns were due to maternal investment in individual eggs I would expect to see that body-size differences only imparted by female transplants, which I do not observe.

Reproductive success varied markedly between transplants of different sexes and across sites. In the two smallest patches (DN-a and SF-a) I observed females producing higher numbers of offspring, numbers of families, mean FS, and larger offspring (Table 6). In the two larger patches (BB-a, LR-a) I observed males producing higher numbers of offspring, numbers of families, and larger offspring (Table 6). Thus, there appears to be sex-dependent reproductive success in these sites. It is suggestive that the smallest sites, those with the highest genetic erosion, have the maternal advantage while the larger patches have paternal advantage for migrant fish. A reasonable theoretically and empirically supported hypothesis is that inbreeding in the mitochondrial genome (mtDNA) has resulted in female advantage in the most genetically depauperate patches. Parental investment differences or local adaptation of resident females may confer an advantage to migrant males over migrant females in large patches. An interesting feature of this mtDNA inbreeding hypothesis is that it could explain the high level of transplant introgression in general by depressed sperm motility in resident males, and higher mtDNA fitness of migrant females (Gemmell et al. 2004). The relationship of mtDNA inbreeding to metabolic efficiency could potentially explain the offspring body size differences between the migrant sexes, and compliment the non-sex-dependent heterosis in the nuclear genome. These results emphasis that mtDNA should not be overlooked when considering genetic rescue implementation. 
I did not observe consistent patterns in dispersal between the sexes of migrant fish from in-stream release site and their candidate redd sites (Table 6; Figure 4). However, In BB-a and SF-a reproductive dispersal of translocated individuals demonstrated, as would be predicted, that females generally do not split their clutch into multiple redds. DN-a was a glaring exception. It appears based on this metric that female migrants covered more distance of the stream than did males that reproduced (Table 6; Figure 4). The dispersal of YOY may have serious implications for survival, particularly in flashy and intermittent streams. Dispersal into stream reaches that often lack surface flow and are distant from suitable refugia could be a source of mortality. However, limited dispersal during high flow events could also reduce the alleviation of densitydependent effects and competition when habitat expands. Lineage-dependent dispersal is interesting in that it reflects the hydrologic differences between DV-b and recipient sites. DV-b has had perennial flow since the construction of a Switzer dam in 1970. If adaptive genetic divergence has taking place in response to altered hydrologic regime juvenile dispersal may have different fitness costs and constitute a source of OD. I observed consistent, but not significant, higher dispersal of residents in all recipient sites, except DN-a were the opposite pattern occurred. In DN-a, I observed significantly higher dispersal of transplants that was insensitive to FS threshold (Table 9). In future work I will strive to link dispersal to survival and reproduction.

In conclusion, until future cohorts are examined I cannot rule out the potential for outbreeding depression during subsequent recombination events. However, these results are quite suggestive of genetic rescue. I observed exceedingly successful transplant reproduction, and demonstrated that they had consistently larger offspring. I found that, as predicted, nearly all of these advantages conferred to the migrants and their offspring scale to patch size and (more strongly) initial genetic diversity. This suggests that the previously documented fragmentationmediated genetic erosion was reducing fitness of resident brook trout. Observing an initial posttranslocation cohort during a highly productive year gives us high resolution and statistical power, but does beg the question of what will happen to lineage-dependent survival during the 
selective crunch of a non-favorable year. Monitoring must continue to address these critical questions, but in spite of the caveats these results are quite promising for the management utility of this approach for headwater fish conservation and informing GR implementation for other taxa. 


\section{CHAPTER 5}

\section{MANAGEMENT IMPLICATIONS AND FUTURE RESEARCH}

Avoiding genetic swamping could pose a greater challenge than previously thought, particularly in stochastic environments. Here, by accident my translocation coincided with a highly productive year, which resulted in an opportunity for dramatic introgression. It is worth considering that if habitat conditions had been more unfavorable there may have been no reproduction of migrant fish, or nearly exclusive reproduction of migrant fish (genetic swamping). Finely tuning the number of migrants for translocation in demographically and environmentally stochastic populations will likely remain challenging. A potential solution is to aim low (move fewer migrants) and conduct more frequent translocations.

Potential GR implementation in headwater fish should also consider the sex ratios of the selected migrants. There are going to be advantages to each decision. Females will bring new mtDNA into the population, which could be an additional source of rescue effect or OD. Here, I have some evidence of female migrant advantage in the two smallest and genetically depauperate patches, which may be linked to mtDNA diversity. The importance the mtDNA should not be overlooked in GR-motivated translocations. Males should generally contribute to more families and cover more of the available habitat with reproduction. This has clear benefit in disseminating new genetic diversity widely throughout a habitat. However, from this study I observe no clear pattern in migrant dispersal from release point based on sex, but I observe some evidence that aversion to clutch splitting in female brook trout might allow males more reproductive coverage of available habitat relative to females. Developing further understanding migrant sex-based differences could aid in making predictions and reaching conservation goals.

Due to the overwhelming amount of stream fragmentation, particularly in headwaters, managers are in desperate need of an effective management tools to combat extirpation. GR could provide an effective and affordable strategy for managers of headwater fish, and other patchily distributed organisms. More work is needed to fully understand risks of outbreeding, and any 
potential GR implementation at this point should be cautious, monitored, and have clearly defined goals. Resource managers and scientists that are working on regionally abundant, but patchily distributed organisms should be encouraged to developed well designed and replicated GR studies. Experimental research in wild populations is seemingly the only way forward in establishing the efficacy of GR in increasing population fitness across taxa and life histories. 
Table 1. Habitat and demographic summary of six brook trout habitat patches by sample year. $\widehat{\mathrm{N}}_{\mathrm{c}}$ is the estimated number of brook trout greater than age-1, and $\widehat{\mathrm{N}}_{\text {YOY }}$ is the estimated number of age-0 brook trout. Patch size is the product of patch area and stream length divided by 1000 . The -a or -b suffix on site name and site code denotes above or below dam, respectively.

\begin{tabular}{|c|c|c|c|c|c|c|c|c|}
\hline Site name & $\begin{array}{l}\text { Site } \\
\text { code }\end{array}$ & $\begin{array}{c}\text { Sample } \\
\text { year }\end{array}$ & $\begin{array}{c}\text { Patch } \\
\text { area (ha) }\end{array}$ & $\begin{array}{c}\text { Stream } \\
\text { length }(\mathrm{km})\end{array}$ & $\begin{array}{l}\text { Patch } \\
\text { size }\end{array}$ & $\begin{array}{l}\text { Dam } \\
\text { age }\end{array}$ & Adult $\widehat{N}_{c}$ & $\widehat{N}_{Y O Y}$ \\
\hline Briery Branch-a & BB-a & 2010 & 2438 & 6.14 & 15.0 & 1966 & 366 (296-576) & 236 (139-457) \\
\hline Briery Branch-a & BB-a & 2011 & & & & & $129(104-175)$ & $139(91-215)$ \\
\hline Briery Branch-a & BB-a & 2012 & & & & & 87 (74-99) & 921(833-1008) \\
\hline Briery Branch-a & BB-a & 2013 & & & & & $474(438-510)$ & 1876(1641-2112) \\
\hline Dry Run-a & $\mathrm{DN}-\mathrm{a}$ & 2010 & 1217 & 8.06 & 9.8 & 1968 & $83(78-156)$ & $117(86-367)$ \\
\hline Dry Run-a & $\mathrm{DN}-\mathrm{a}$ & 2011 & & & & & $47(46-48)$ & $30(29-31)$ \\
\hline Dry Run-a & DN-a & 2012 & & & & & $37(34-40)$ & 718(656-781) \\
\hline Dry Run-a & DN-a & 2013 & & & & & $529(523-535)$ & 771(706-836) \\
\hline Dry River-a & DV-a & 2010 & 3807 & 27.6 & 105.1 & 1970 & 1982 (1726-2202) & 1285 (843-2077) \\
\hline Dry River-a & DV-a & 2011 & & & & & 616 (529-719) & 1009 (795-1275) \\
\hline Dry River-a & DV-a & 2012 & & & & & $555^{*}$ & $3203 *$ \\
\hline Dry River-a & DV-a & 2013 & & & & & $1759 *$ & $4792^{*}$ \\
\hline Dry River-b & DV-b & 2010 & 10880 & 40 & 435.2 & - & - & - \\
\hline Dry River-b & DV-b & 2011 & & & & - & - & - \\
\hline Little River-a & LR-a & 2010 & 4121 & 12.7 & 52.3 & 1965 & 728 (637-873) & $463(347-633)$ \\
\hline Little River-a & LR-a & 2011 & & & & & $323(236-438)$ & 677 (519-882) \\
\hline Little River-a & LR-a & 2012 & & & & & 270 (244-297) & $3978(3702-4255)$ \\
\hline Little River-a & LR-a & 2013 & & & & & $1147^{*}$ & $2105^{*}$ \\
\hline Skidmore Fork-a & SF-a & 2010 & 993 & 5.11 & 5.1 & 1962 & $268(231-346)$ & $47(42-130)$ \\
\hline Skidmore Fork-a & SF-a & 2011 & & & & & $90(73-130)$ & 70 (50-117) \\
\hline Skidmore Fork-a & SF-a & 2012 & & & & & 84 (75-93) & 929(832-1025) \\
\hline Skidmore Fork-a & SF-a & 2013 & & & & & $374(333-415)$ & 1189 (913-1466) \\
\hline
\end{tabular}


Table 2. Genetic summary statistics of brook trout cohorts (young-of-year [YOY]) from six habitat patches and Coursey Springs hatchery. NG is the number of genetic samples used for the following genetic metrics. HW and LD are the number of significant tests of Hardy-Weinberg and linkage disequilibrium following sequential Bonferroni correction. RS denotes the metrics calculated from the random subset of the data selecting one individual per family. $\widehat{N}_{\text {Fam }}$ is the number of sampled full-sibling families. FE is a family evenness a metric representing variance in family size (refer to the methods of this transcript for the equation). $\widehat{N}_{b}$ is the LDNe-based single-sample estimate of the effective number of breeders that gave rise to that year's YOY. The -a or -b suffix on site name and site code denotes above or below dam, respectively.

\begin{tabular}{|c|c|c|c|c|c|c|c|c|c|c|c|c|c|c|c|}
\hline Site name & $\begin{array}{c}\text { Site } \\
\text { code }\end{array}$ & $\begin{array}{c}\text { Sample } \\
\text { Year }\end{array}$ & $N_{\mathrm{G}}$ & HW & LD & Ao & $\begin{array}{l}\text { Ao } \\
\text {-RS }\end{array}$ & AR & $\begin{array}{l}\text { AR } \\
\text {-RS }\end{array}$ & $\mathrm{H}_{\mathrm{S}}$ & $\begin{array}{c}\mathrm{H}_{\mathrm{S}} \\
-\mathrm{RS}\end{array}$ & $\widehat{N}_{\text {Fam }}$ & $\begin{array}{c}\text { Mean } \\
\text { FS }\end{array}$ & $\mathrm{FE}$ & $\widehat{N}_{b}$ \\
\hline Dry River-b & DV-b & 2010 & 99 & 0 & 3 & 8.8 & 8.6 & 7.8 & 6.6 & 0.777 & 0.781 & 57 & 1.7 & 0.949 & $191.2(140.3-279.8)$ \\
\hline Dry River-b & DV-b & 2011 & 67 & 0 & 5 & 9.4 & 8.8 & 8.0 & 6.7 & 0.771 & 0.786 & 41 & 1.6 & 0.970 & $152.8(111.5-227.2)$ \\
\hline Briery Branch-a & BB-a & 2010 & 129 & 0 & 17 & 7.4 & 7.0 & 6.7 & 6.0 & 0.731 & 0.710 & 25 & 2.9 & 0.866 & $26.2(20.7-33.0)$ \\
\hline Briery Branch-a & BB-a & 2011 & 91 & 5 & 14 & 7.9 & 7.6 & 6.6 & 6.1 & 0.703 & 0.741 & 30 & 3.0 & 0.834 & $32.6(26.1-40.6)$ \\
\hline Briery Branch-a & BB-a & 2012 & 572 & 8 & 28 & 10.0 & 9.4 & 7.7 & 6.5 & 0.752 & 0.762 & 71 & 8.9 & 0.897 & $41.7(38-45.6)$ \\
\hline Dry Run-a & $\mathrm{DN}-\mathrm{a}$ & 2010 & 84 & 2 & 15 & 3.4 & 3.4 & 3.4 & 3.3 & 0.565 & 0.576 & 15 & 3.1 & 0.925 & $4.9(3.8-8.7)$ \\
\hline Dry Run-a & $\mathrm{DN}-\mathrm{a}$ & 2011 & 27 & 0 & 2 & 2.8 & 2.6 & 2.8 & 2.6 & 0.392 & 0.396 & 13 & 2.1 & 0.941 & $40.2(12.6-\infty)$ \\
\hline Dry Run-a & DN-a & 2012 & 546 & 8 & 28 & 6.9 & 6.4 & 5.7 & 4.8 & 0.649 & 0.628 & 46 & 11.9 & 0.907 & $24(21.2-26.9)$ \\
\hline Little River-a & LR-a & 2010 & & 5 & 26 & & 8.9 & & 5.9 & & & & 3.4 & & \\
\hline Little River-a & LR-a & 2011 & 383 & 8 & 27 & 8.8 & 8.4 & 6.8 & 5.8 & 0.717 & 0.710 & 90 & 4.2 & 0.923 & $53.9(44.0-65.2)$ \\
\hline Little River-a & LR-a & 2012 & 2333 & 7 & 27 & 10.6 & 10.1 & 7.8 & 6.3 & 0.735 & 0.724 & 145 & 3.8 & 0.918 & 79.7 (67.9-93.0) \\
\hline Dry River-a & DV-a & 2010 & 403 & 8 & 27 & 10.9 & 10.4 & 8.2 & 7.1 & 0.780 & 0.794 & 106 & 3.6 & 0.899 & $66.6(57.8-76.5)$ \\
\hline Dry River-a & DV-a & 2011 & 524 & 8 & 28 & 11.8 & 11.4 & 8.8 & 7.1 & 0.796 & 0.787 & 139 & 3.7 & 0.900 & 75.0 (60.9-91.4) \\
\hline Dry River-a & DV-a & 2012 & 303 & 1 & 1 & 10.5 & 10.1 & 8.4 & 7.0 & 0.784 & 0.788 & 60 & 1.4 & 0.975 & 166.2(125.6-232.6) \\
\hline Skidmore Fork-a & SF-a & 2010 & 41 & 6 & 9 & 5.4 & 4.9 & 4.8 & 4.9 & 0.542 & 0.622 & 12 & 4.2 & 0.852 & $10.1(5.2-15.1)$ \\
\hline Skidmore Fork-a & SF-a & 2011 & 50 & 2 & 7 & 4.1 & 4.0 & 3.9 & 3.9 & 0.519 & 0.564 & 14 & 3.6 & 0.924 & 17.1 (10.5-26.5) \\
\hline Skidmore Fork-a & SF-a & 2012 & 543 & 8 & 28 & 7.9 & 7.0 & 5.5 & 5.2 & 0.629 & 0.655 & 47 & 13.1 & 0.914 & 14.5(12.4-16.8) \\
\hline Coursey Springs & $\mathrm{CS}$ & 2012 & 53 & 0 & 1 & 5.4 & & 4.8 & & 0.709 & & 37 & 1.4 & 0.968 & $152.3(83.2-454.5)$ \\
\hline
\end{tabular}


Table 3. Percent change of demographic and genetic summary statistics following translocation. All metrics are calculated as percent change from 2011 to 2012, except $\widehat{N}_{c}$ (brook trout greater than age-0), which was calculated as percent change from 2011 to 2013. Refer to Table 1 and Table 2 above for metric definitions. Occupied reaches are the number of 50-meter sections that were occupied with YOY. Site codes that are followed by an asterisk denotes that the site was not comprehensively sampled or genotyped in 2012 therefore changes in $\widehat{N}_{\text {Fam }}$, FE, and Mean FS are likely an artifact of sampling.

\begin{tabular}{cccccccccc}
\hline & \multicolumn{10}{c}{ Percent change pre-post translocations } \\
\cline { 2 - 10 } Site code & $\widehat{N}_{Y O Y}$ & $\widehat{N}_{c}$ & $\widehat{N}_{\text {Fam }}$ & FE & Mean FS & AR & $\mathrm{H}_{\mathrm{S}}$ & $\widehat{N}_{b}$ & $\begin{array}{c}\text { Occupied } \\
\text { Sections }\end{array}$ \\
\hline BB-a & 662.6 & 267.4 & 136.7 & 7.5 & 197.2 & 17.8 & 7.0 & 27.9 & 52.6 \\
DN-a & 2393.3 & 937.3 & 253.8 & -3.6 & 471.5 & 108.2 & 65.7 & $-40.3^{*}$ & 237.5 \\
SF-a & 1327.1 & 315.6 & 235.7 & -1.0 & 268.2 & 41.6 & 21.0 & -15.2 & 29.4 \\
LR-a* & 587.6 & 255.1 & 61.1 & -0.5 & -10.4 & 14.0 & 2.5 & 47.9 & 32.4 \\
DV-a* & 317.4 & 185.6 & -56.8 & 8.3 & -61.4 & -4.5 & -1.5 & 121.6 & - \\
(control) & & & & & & & & & \\
\hline
\end{tabular}

Table 4. Results of randomization tests of neutral introgression of transplanted brook trout at the family level in the $2012 F_{1}$ cohort. Transplant representation is the proportional representation of translocated individuals in the $2011 \widehat{N}_{c}$ for each population. Within each lineage class and population, the expected and observed numbers of families are reported. The one-sided p-values from the estimated null distributions are reported (lower-tail probability for RR and upper-tail for RT and TT).

\begin{tabular}{ccccc}
\hline \multirow{2}{*}{$\begin{array}{c}\text { Site } \\
\text { code }\end{array}$} & Transplant & \multicolumn{3}{c}{ Expected (Obs) Full-sibling FS } \\
\cline { 3 - 5 } representation & RR & RT & TT \\
\hline BB-a & 0.0775 & $61(52) ; P=0.006$ & $10(15) ; P=0.039$ & $0(4) ; P=0.0$ \\
DN-a & 0.1961 & $20(24) ; P=0.058$ & $15(21) ; P=0.022$ & $1(1) ; P=0.492$ \\
SF-a & 0.1111 & $37(30) ; P=0.013$ & $9(14) ; P=0.035$ & $0(3) ; P=0.002$ \\
LR-a & 0.0310 & $136(133) ; P=0.176$ & $9(12) ; P=0.088$ & $0(0) ; P=0.131$ \\
\hline
\end{tabular}


Table 5. Summary of observed reproduction and parentage assignment efficacy in each recipient population in the 2012 F1 cohort by lineage. Diagnostic alleles is the average number of diagnostic alleles per family by lineage. \% PA is the percentage of offspring with parents assigned by lineage.

\begin{tabular}{|c|c|c|c|c|c|c|c|c|c|c|c|c|c|c|c|}
\hline \multirow[b]{2}{*}{$\begin{array}{l}\text { Site } \\
\text { code }\end{array}$} & \multicolumn{3}{|c|}{$\widehat{\mathrm{N}}_{\text {YOY }}$} & \multicolumn{3}{|c|}{$\widehat{\mathrm{N}}_{\text {fam }}$} & \multicolumn{3}{|c|}{ Mean FS } & \multicolumn{3}{|c|}{$\begin{array}{c}\text { Diagnostic } \\
\text { Alleles }\end{array}$} & \multicolumn{3}{|c|}{$\% \mathrm{PA}$} \\
\hline & $\mathrm{RR}$ & $\mathrm{RT}$ & $\mathrm{TT}$ & $\mathrm{RR}$ & $\mathrm{RT}$ & $\mathrm{TT}$ & $\mathrm{RR}$ & $\mathrm{RT}$ & $\mathrm{TT}$ & $\mathrm{RR}$ & RT & $\mathrm{TT}$ & $\mathrm{RR}$ & RT & $\mathrm{TT}$ \\
\hline BB-a & 397 & 199 & 37 & 52 & 15 & 4 & 7.6 & 13.3 & 9.3 & 0.08 & 2.93 & 4.50 & 78 & 98 & 100 \\
\hline DN-a & 231 & 293 & 22 & 24 & 21 & 1 & 9.6 & 14.0 & 22.0 & 0.04 & 5.19 & 9.00 & 18 & 72 & 100 \\
\hline SF-a & 383 & 212 & 23 & 30 & 14 & 3 & 12.8 & 15.1 & 7.7 & 0.03 & 5.64 & 8.67 & 69 & 87 & 100 \\
\hline LR-a & 492 & 52 & & 133 & 12 & - & 3.7 & 4.3 & - & 0.00 & 1.58 & - & 47 & 66 & - \\
\hline
\end{tabular}

Table 6. Transplant reproductive success, dispersal, and offspring body size by sex. $\widehat{\mathbf{N}}_{\text {Fam }}$, $\mathbf{N}_{\text {Yoy }}$, and Mean FS were summarized so that if a transplant of a given sex contributed to a family it was counted towards that sex (Note: families of TT lineage would be counted towards both sexes). Release dispersal is the mean absolute distance of each family centroid to the release point of that individual parent. Reproductive dispersal is the mean pairwise distance of all families belonging to a given parent. Total length (TL) was only calculated for RT crosses to isolate any sexdependent parental difference on offspring body size. Significant values at $\alpha=0.05$ are shown in bold for TL

\begin{tabular}{|c|c|c|c|c|c|c|c|c|c|c|c|c|}
\hline \multirow[b]{2}{*}{ Site name } & \multicolumn{2}{|c|}{$\widehat{N}_{f a m}$} & \multicolumn{2}{|c|}{$N_{o f f}$} & \multicolumn{2}{|c|}{ FS } & \multicolumn{2}{|c|}{$\begin{array}{c}\text { Mean } \\
\text { Release } \\
\text { Dispersal } \\
\end{array}$} & \multicolumn{2}{|c|}{$\begin{array}{c}\text { Mean } \\
\text { Reproductive } \\
\text { Dispersal }\end{array}$} & \multicolumn{2}{|c|}{ TL } \\
\hline & $\mathrm{M}$ & $\mathrm{F}$ & $\mathrm{M}$ & $F$ & $\mathrm{M}$ & $F$ & $\mathrm{M}$ & $\mathrm{F}$ & $\mathrm{M}$ & $F$ & $\mathrm{M}$ & $F$ \\
\hline BB-a & 14 & 9 & 158 & 115 & 11.3 & 12.8 & 529.2 & 1041.7 & 424.5 & 5.6 & 87.0 & 85.1 \\
\hline $\mathrm{DN}-\mathrm{a}$ & 8 & 15 & 104 & 233 & 13.0 & 15.5 & 436.1 & 389.2 & 279.2 & 349.8 & 79.9 & 81.5 \\
\hline SF-a & 9 & 11 & 83 & 175 & 9.2 & 15.9 & 143.8 & 235.7 & 156.7 & 14.3 & 74.4 & 75.8 \\
\hline LR-a & 7 & 5 & 35 & 17 & 5.0 & 3.4 & 1420.8 & 1243.8 & - & - & 82.5 & 79.5 \\
\hline
\end{tabular}


Table 7. Correlations of habitat and genetic metrics to observed percent demographic change after translocations in recipient sites. Metrics of interest are patch size, 2011 to 2012 percent increase in occupied 50 m reaches (all individuals and YOY), 2011 allelic richness, and 2011 mean expected heterozygosity. Kendall's $\boldsymbol{\tau}$ was calculated and statistical test conducted with no ties. One-sided p-values are reported, and should be considered cautiously, give sample size $(N=4)$.

\begin{tabular}{cccc}
\hline Metric & $\tau$ & $T$ & $P$-value \\
\hline & \multicolumn{3}{c}{$\Delta \widehat{N}_{Y O Y}$} \\
\cline { 2 - 4 } Patch Size & 0.667 & 1 & 0.167 \\
Total Occupancy & 0.334 & 4 & 0.834 \\
YOY Occupancy & 0.334 & 4 & 0.834 \\
AR & -1 & 0 & 0.042 \\
$\mathrm{H}_{\mathrm{s}}$ & -1 & 0 & 0.042 \\
& \multicolumn{3}{c}{$\Delta \widehat{N}_{c}$} \\
\cline { 2 - 4 } Patch Size & -0.667 & 1 & 0.167 \\
Total Occupancy & 0.334 & 4 & 0.834 \\
YOY Occupancy & 0.334 & 4 & 0.834 \\
AR & -1 & 0 & 0.042 \\
$\mathrm{H}_{\mathrm{s}}$ & -1 & 0 & 0.042 \\
\hline
\end{tabular}


Table 8. AICc model comparison of negative binomial family generalized linear models predicting full-sibling family size. The global model included pseudo-midparent length (PmP) and three-category lineage class (RR, RT, TT) as predictors of full-sibling family size.

\begin{tabular}{|c|c|c|c|c|c|}
\hline Model & $K$ & $N$ & $A I C C$ & $\triangle A I C c$ & $\log (L)$ \\
\hline & \multicolumn{5}{|c|}{ BB-a } \\
\hline PmP & 2 & 55 & 369.1 & 0.000 & -181.5 \\
\hline Null & 1 & & 373.2 & 4.014 & -184.5 \\
\hline Global & 4 & & 373.5 & 4.365 & -181.4 \\
\hline \multirow[t]{2}{*}{ Lineage } & 3 & & 375.6 & 6.418 & -183.5 \\
\hline & \multicolumn{5}{|c|}{ DN-a } \\
\hline Null & 1 & 28 & 205.3 & 0.000 & -100.5 \\
\hline PmP & 2 & & 205.3 & 0.014 & -99.4 \\
\hline Lineage & 3 & & 208.3 & 3.002 & -99.6 \\
\hline \multirow[t]{2}{*}{ Global } & 4 & & 209.5 & 4.217 & -98.9 \\
\hline & \multicolumn{5}{|c|}{ SF-a } \\
\hline Global & 4 & 33 & 234.3 & 0.000 & -111.5 \\
\hline $\mathrm{PmP}$ & 2 & & 235.7 & 1.409 & -114.7 \\
\hline Null & 1 & & 245.4 & 11.075 & -120.6 \\
\hline Lineage & 3 & & 248.7 & 14.365 & -119.9 \\
\hline
\end{tabular}

Table 9. AICc model comparison of linear mixed models predicting $2012 \mathrm{~F}_{1}$ Cohort individual body size. The global model included pseudo-midparent length (PmP) and three-category lineage class (RR, RT, TT) as predictors, with family membership as a random effect.

\begin{tabular}{cccccc}
\hline Model & $K$ & $N$ & \multicolumn{5}{c}{$A I C C$} & $\Delta A I C C$ & $\log (L)$ \\
\hline & \multicolumn{5}{c}{ BB-a } \\
\cline { 2 - 6 } PmP & 4 & 560 & 3695.167 & 0.000 & -1843.5 \\
Global & 6 & & 3695.792 & 0.625 & -1841.8 \\
Lineage & 5 & \multicolumn{5}{c}{3709.278} & 14.111 & -1849.6 \\
Null & 3 & \multicolumn{5}{c}{3715.395} & 20.228 & -1854.7 \\
& \multicolumn{5}{c}{ DN-a } \\
Global & 6 & 364 & 2223.104 & 0.000 & -1105.4 \\
PmP & 4 & \multicolumn{5}{c}{2224.862} & 1.759 & -1108.4 \\
Lineage & 5 & \multicolumn{5}{c}{2230.410} & 7.307 & -1110.1 \\
Null & 3 & \multicolumn{5}{c}{2236.342} & 13.238 & -1115.1 \\
& \multicolumn{5}{c}{ SF-a } \\
Lineage & 5 & 471 & 3044.152 & 0.000 & -1517.0 \\
Null & 3 & \multicolumn{5}{c}{3045.479} & 1.327 & -1519.7 \\
Global & 6 & \multicolumn{5}{c}{3046.048} & 1.896 & -1516.9 \\
PmP & 4 & \multicolumn{5}{c}{3046.718} & 2.566 & -1519.3 \\
\hline
\end{tabular}


Table 10. Two-sample tests of total length, FS, and family dispersal by lineage class at the family level. For each population there were 10 tests per metric, 5 per each lineage class (R-T or RR-RT; excluding LR-a which had no TT families), and one test at each FS threshold (1-5). Sequential Bonferroni correction was applied across the five FS thresholds within each lineage class and population. The numbers of significant tests are reported with the threshold FS at which each occurred (given as a superscript). The mean of mean differences $\left(\overline{\boldsymbol{x}}_{\boldsymbol{D}}\right)$ and range across all FS thresholds were reported within each lineage class. T-tests were used for total length and Wilcoxon rank-sum tests were used for FS and family dispersal.

\begin{tabular}{|c|c|c|c|c|}
\hline \multirow{3}{*}{ Site code } & \multicolumn{4}{|c|}{ Total Length } \\
\hline & \multicolumn{2}{|l|}{$\mathrm{R}-\mathrm{T}$} & \multicolumn{2}{|l|}{ RR-RT } \\
\hline & $\bar{x}_{D}$ & Significant tests & $\bar{x}_{D}$ & Significant tests \\
\hline BB-a & $-4.2(-5.6-(-3.2))$ & $1^{1}$ & $-5.3(-7-(-4.3))$ & $2^{1,3}$ \\
\hline $\mathrm{DN}-\mathrm{a}$ & $-5.5(-6.2-(-4.6))$ & 5 & $-5.6(-6.3-(-4.6))$ & 5 \\
\hline SF-a & $-4.7(-5.3-(-4.2))$ & 5 & $-4.9(-5.6-(-4.5))$ & 5 \\
\hline \multirow[t]{4}{*}{ LR-a } & - & & $-3.6(-6.1-(-1.3))$ & $1^{1}$ \\
\hline & \multicolumn{4}{|c|}{ Full-Sibling FS } \\
\hline & \multicolumn{2}{|c|}{$\mathrm{R}-\mathrm{T}$} & \multicolumn{2}{|l|}{ RR-RT } \\
\hline & $\bar{x}_{D}$ & Significant tests & $\bar{x}_{D}$ & Significant tests \\
\hline BB-a & $-5.2(-5.8-(-4.1))$ & 0 & $-6.4(-7.3-(-5.5))$ & 0 \\
\hline $\mathrm{DN}-\mathrm{a}$ & $-6.9(-8.2-(-4.7))$ & $1^{2}$ & $-6.7(-8-(-4.3))$ & 0 \\
\hline SF-a & $0.3(-1.1-1.7)$ & 0 & $-0.5(-2.4-0.8)$ & 0 \\
\hline \multirow[t]{4}{*}{ LR-a } & & & $0.2(-1.1-1.8)$ & 0 \\
\hline & \multicolumn{4}{|c|}{ Family Dispersal } \\
\hline & \multicolumn{2}{|c|}{$\mathrm{R}-\mathrm{T}$} & \multicolumn{2}{|c|}{ RR-RT } \\
\hline & $\bar{x}_{D}$ & Significant tests & $\bar{x}_{D}$ & Significant tests \\
\hline BB-a & $26.9(18.2-49.3)$ & 0 & $12.4(3.7-31.7)$ & 0 \\
\hline $\mathrm{DN}-\mathrm{a}$ & $-173(-228.9-(-90.6))$ & $3^{3,4,5}$ & $-182.6(-242.2-(-94.6))$ & $2^{4,5}$ \\
\hline $\mathrm{SF}-\mathrm{a}$ & 23.9 (14.5-29.9) & 0 & 29.8 (15.7-38.3) & 0 \\
\hline LR-a & - & - & $12.2(-62.4-100.9)$ & 0 \\
\hline
\end{tabular}




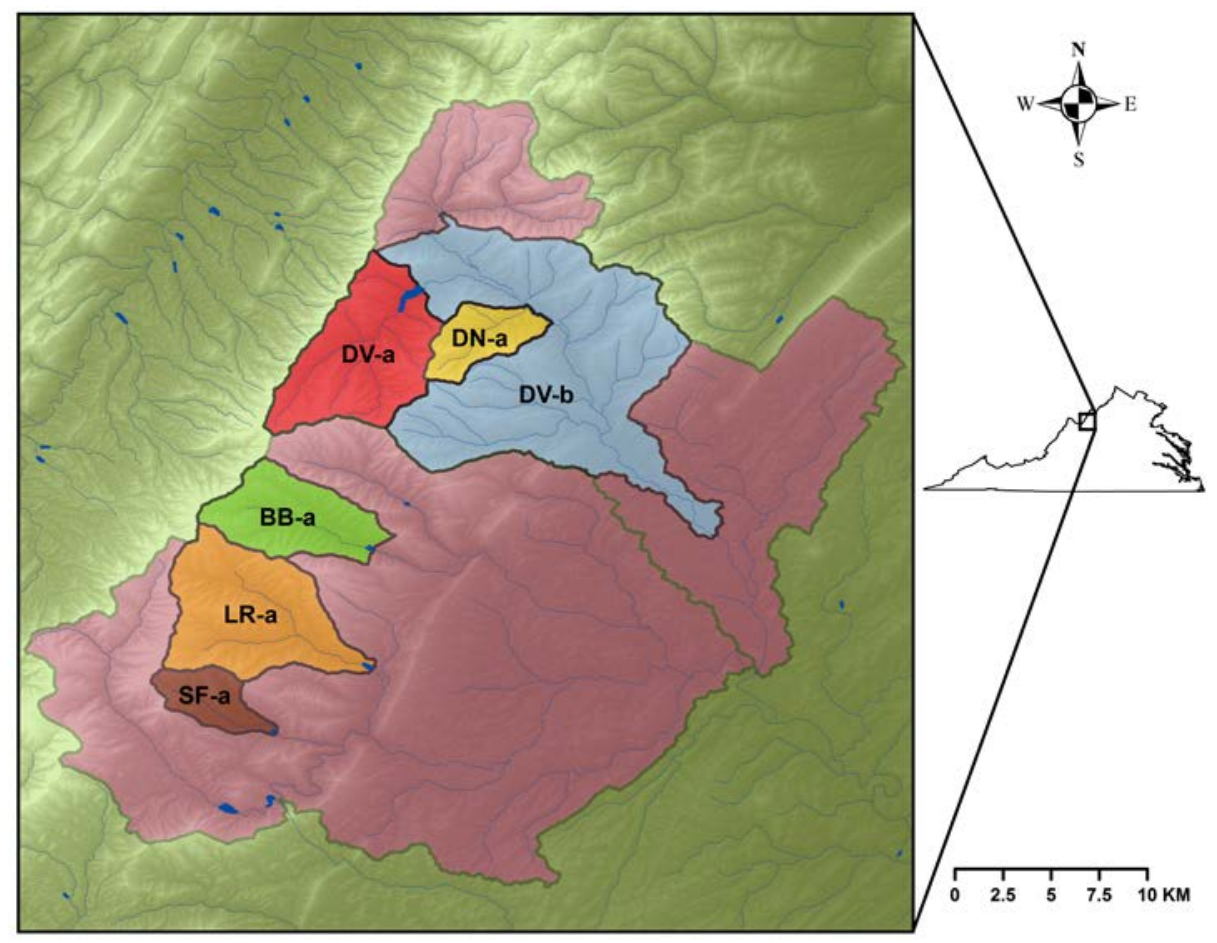

Figure 1. Map of study area in north central Virginia, USA. The six brook trout patches examined in this study are shown above. DV, Dry River; DN, Dry Run; BB, Briery Branch; LR, Little River; SF, Skidmore Fork. Above-dam sites are denoted by -a, below-dam sites are denoted by -b. The wider boundary represents the hypothesized historical range of brook trout in this river system. DN-a, BB-a, LR-a, and SF-a were recipient's of translocated brook from DV-b. No brook trout were translocated trout to DV-a, and it serves as a control in this study. 

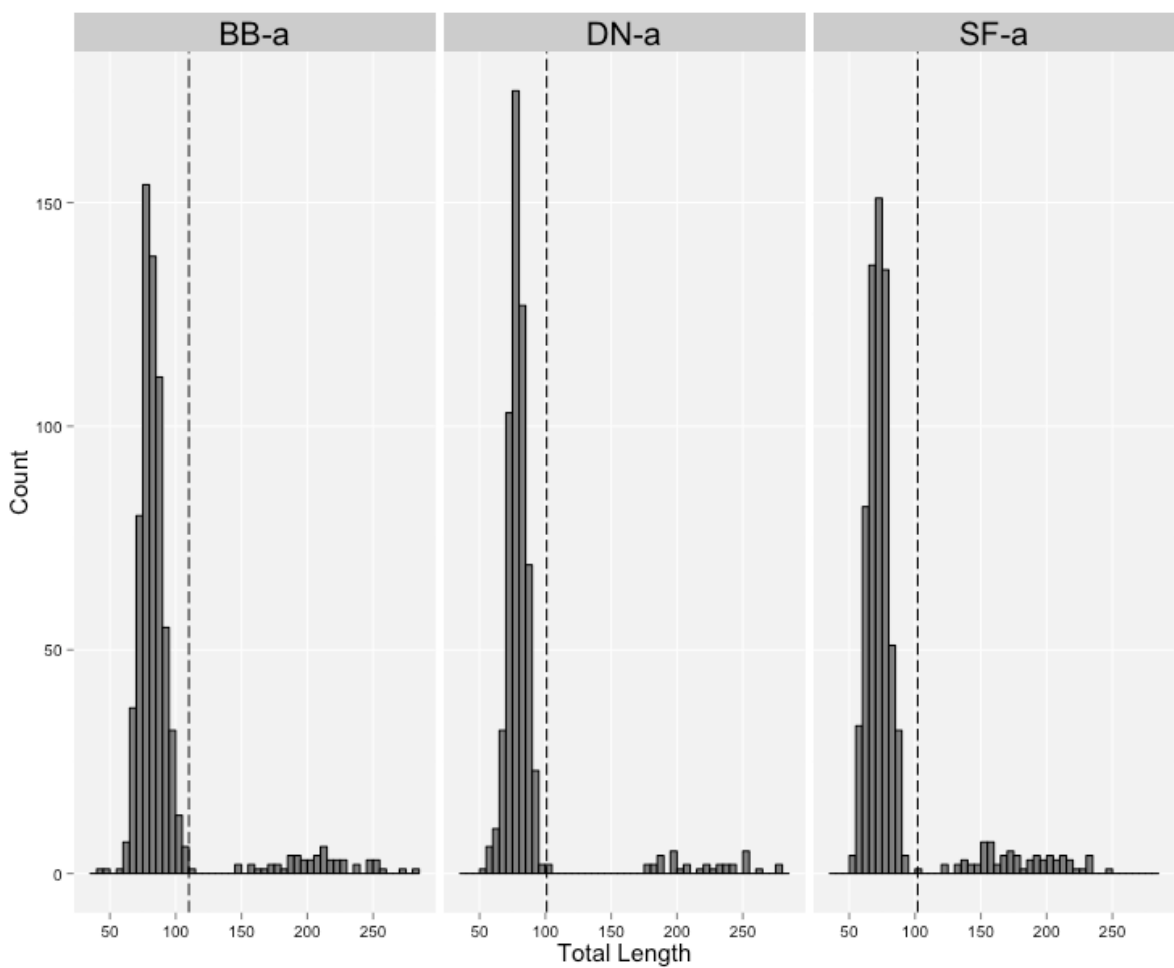

Figure 2. Length frequency histograms of brook by site and sample year. Vertical dotted line is meant to demonstrate the efficacy of length cut offs for discriminating young-of-year (YOY) from fish age-1 and older. The three histograms include all captured brook trout from 2012 in BB-a, DN-a, and SF-a. 


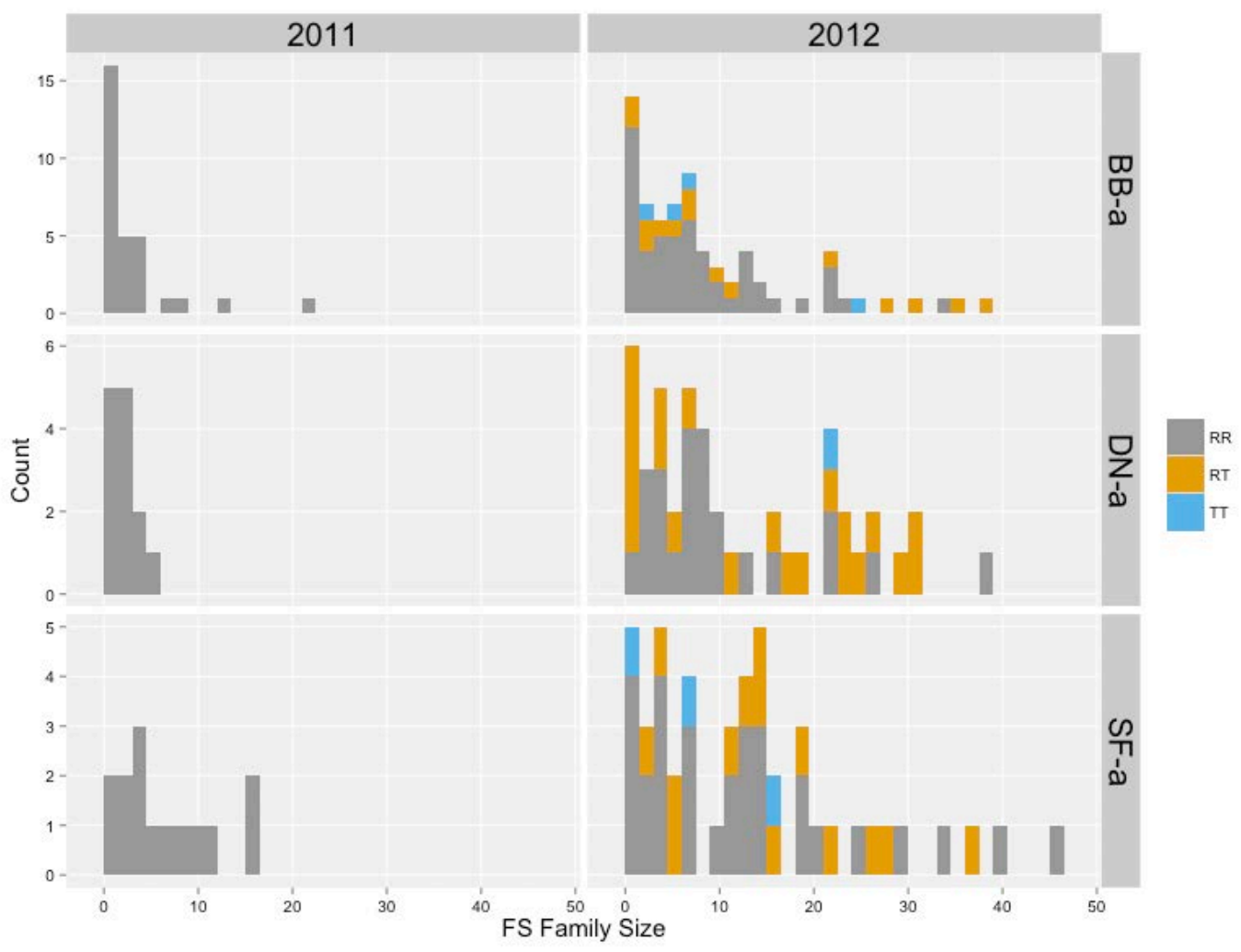

Figure 3. Histograms of full-sibling family size (FS) by site. 2011 FS distribution (left) and 2012 FS distribution (right) as reconstructed by program Colony. The histogram for 2012 (posttranslocation) is color coded by lineage class. 

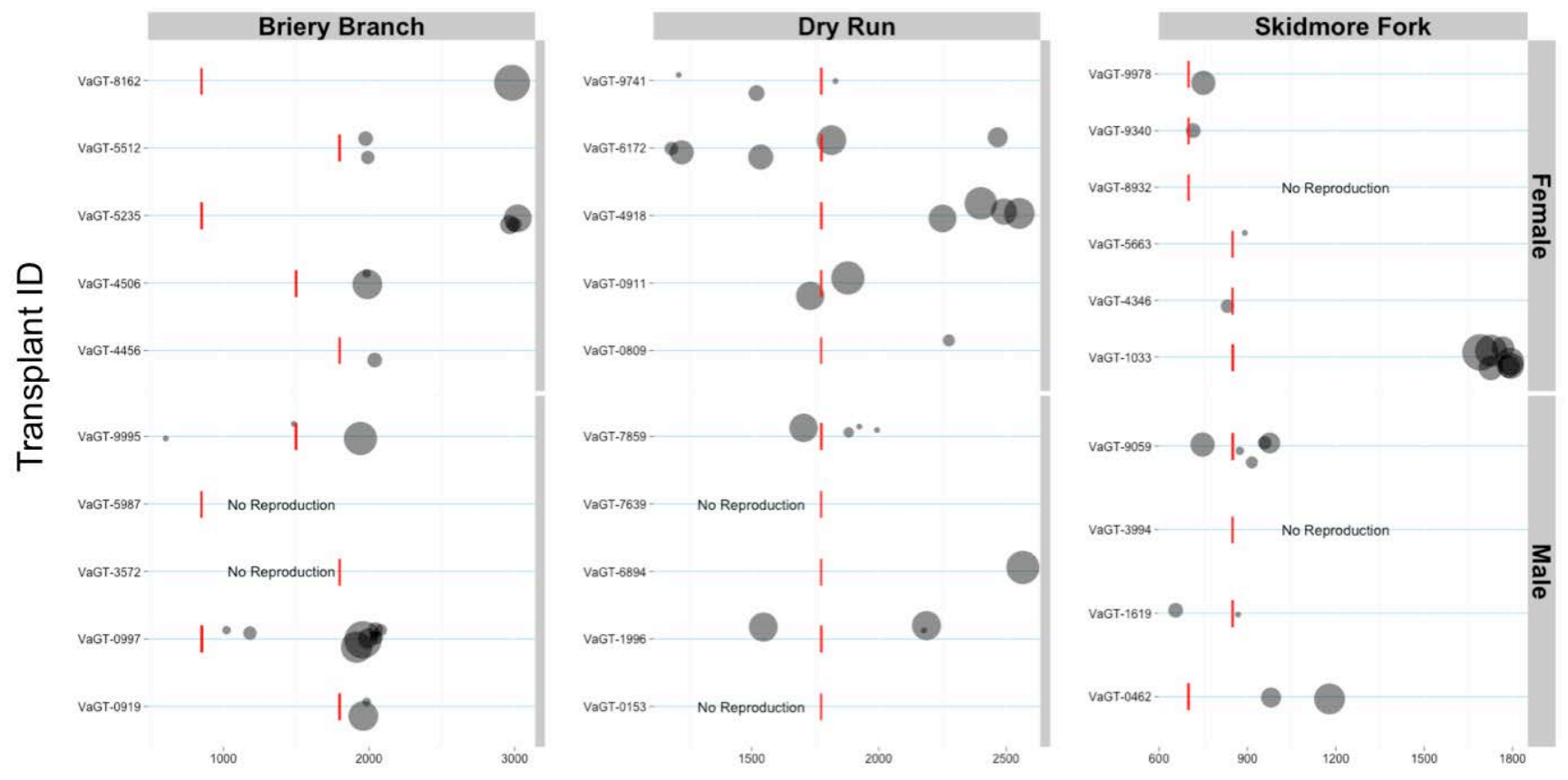

Family Centroid

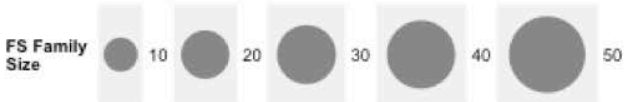

Figure 4. Within-stream family centroid locations of transplant produced families. The y-axis contains transplant identification names (ID), and the $\mathrm{x}$-axis is the upstream distance from the lake. The horizontal panels contain site and the vertical panels separate transplant parents by sex. The point representing each family is scaled to full-sibling family size. Vertical bars represent release locations of transplant parents, and “No Reproduction” denotes that no families were sampled for that transplant individual. 


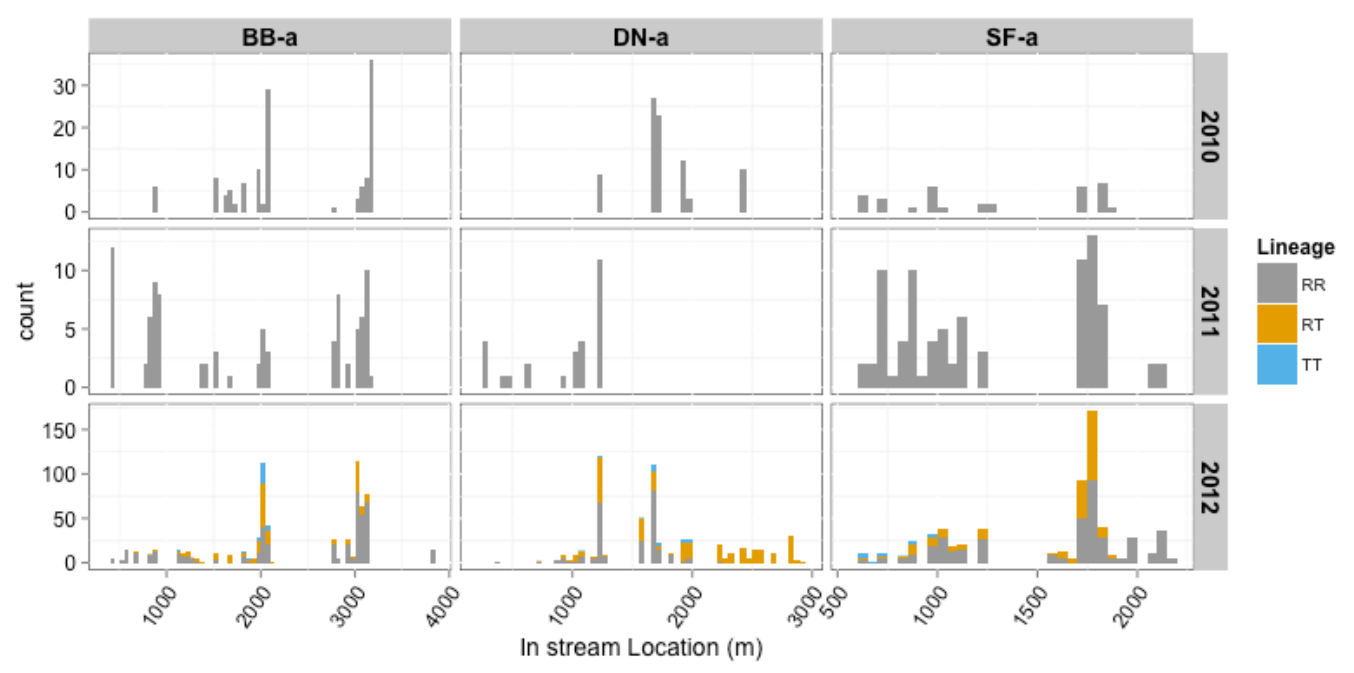

Figure 5. In stream distribution of young of year brook trout across sites and sample year. The $x-$ axis is the location (binned to $50 \mathrm{~m}$ section) of brook trout occurrence for the years 2010, 2011, and 2012. Relative abundance of each lineage in 2012 is represented by fill color within each 50 m bin. 


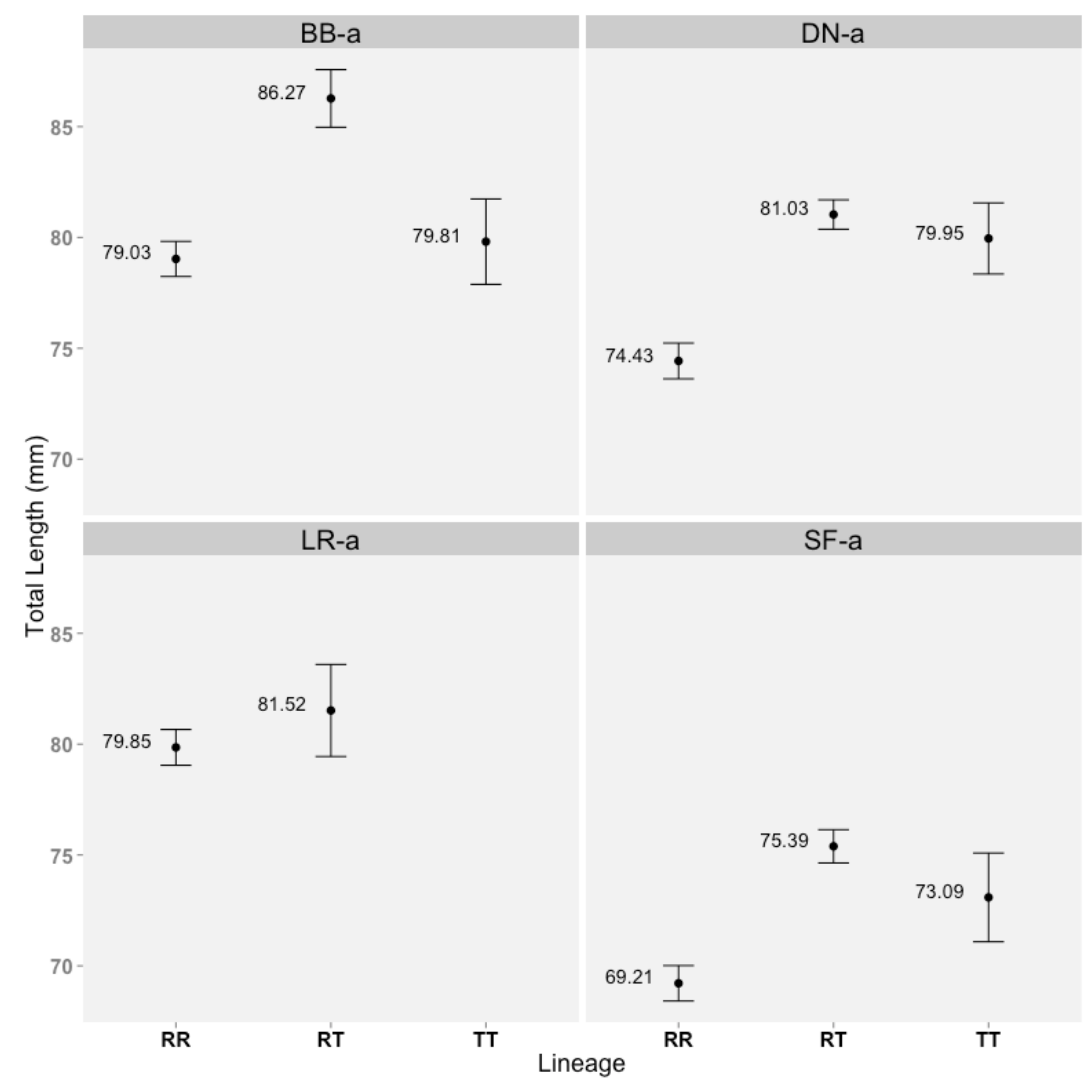

Figure 6. Mean and 95\% confidence intervals of total length (TL; nearest millimeter) by lineage. These values are at the individual level, and have not been aggregated to the family level as was conducted for significant testing. 

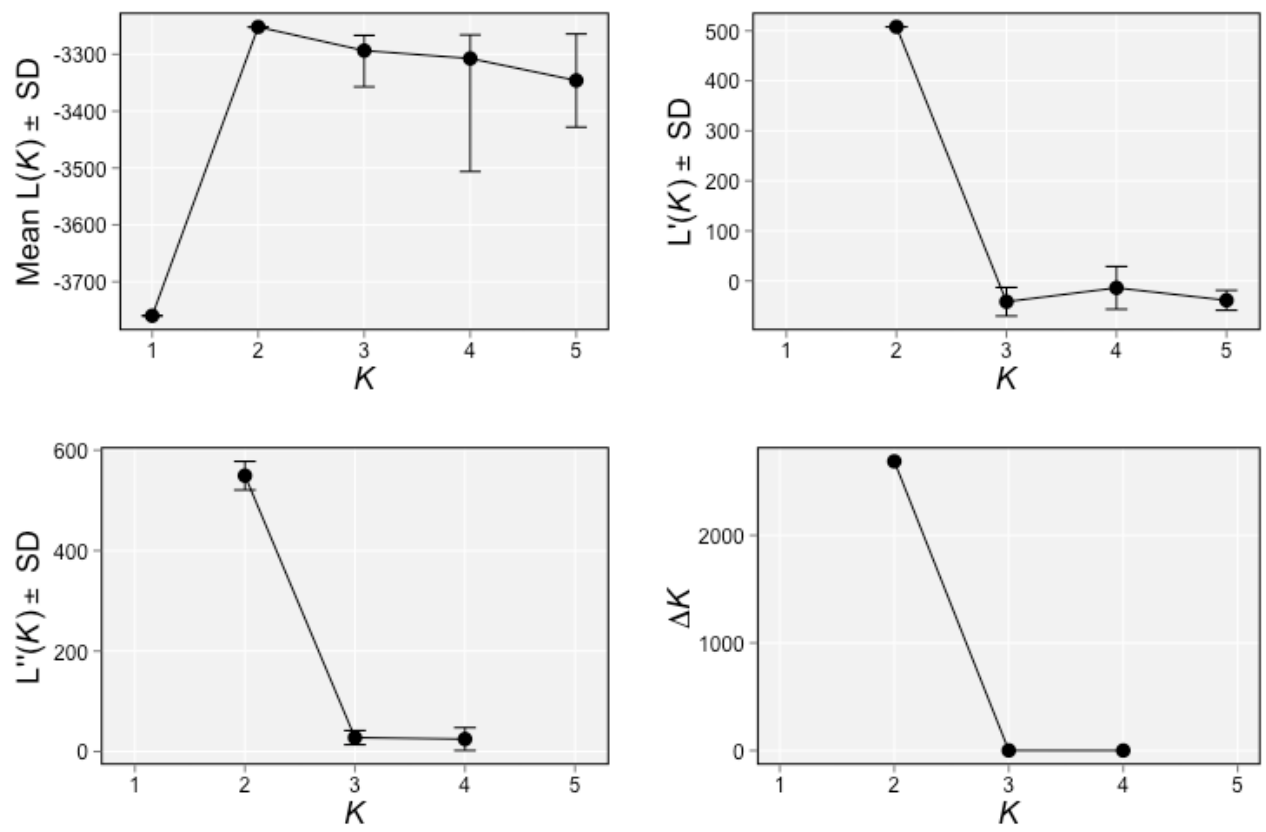

Figure 7. Summary of STRUCTURE results for hatchery and DV-b brook trout. I used 10 replicates for each value of $K 1-5$ (refer to method section of this manuscript for STRUCTURE parameter set details). The raw log likelihood $L(K)$, first derivative $L^{\prime}(K)$, second derivative $L^{\prime \prime}(K)$, and $\Delta K$ graphs follow the Evanno method. $K=2$ was overwhelmingly supported by all lines of evidence.

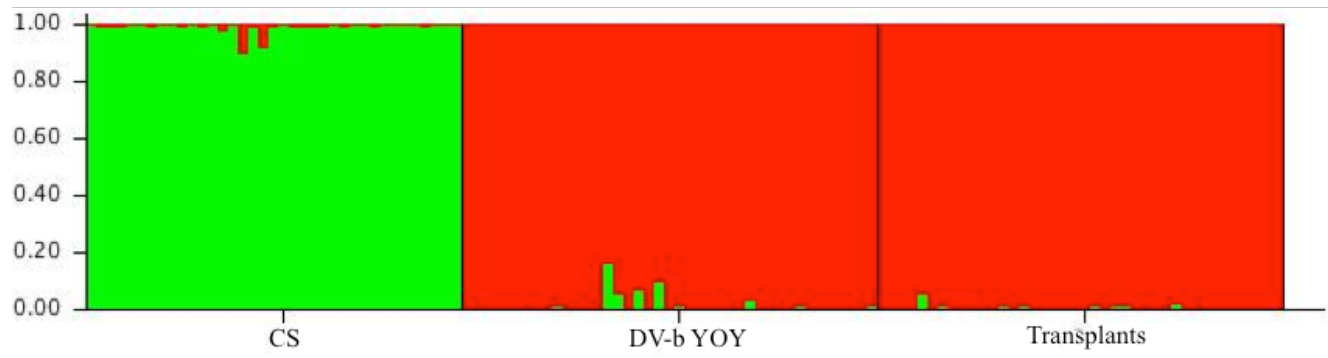

Figure 8. Bar plot from the program STRUCTURE with $K=2$. The left panel contains all the Coursey Springs Hatchery fish (CS), the center panel contains young-of year captured in 2010 and 2011 from DV-b, and the right panel contains the translocated adults captured in DV-b in 2011. 

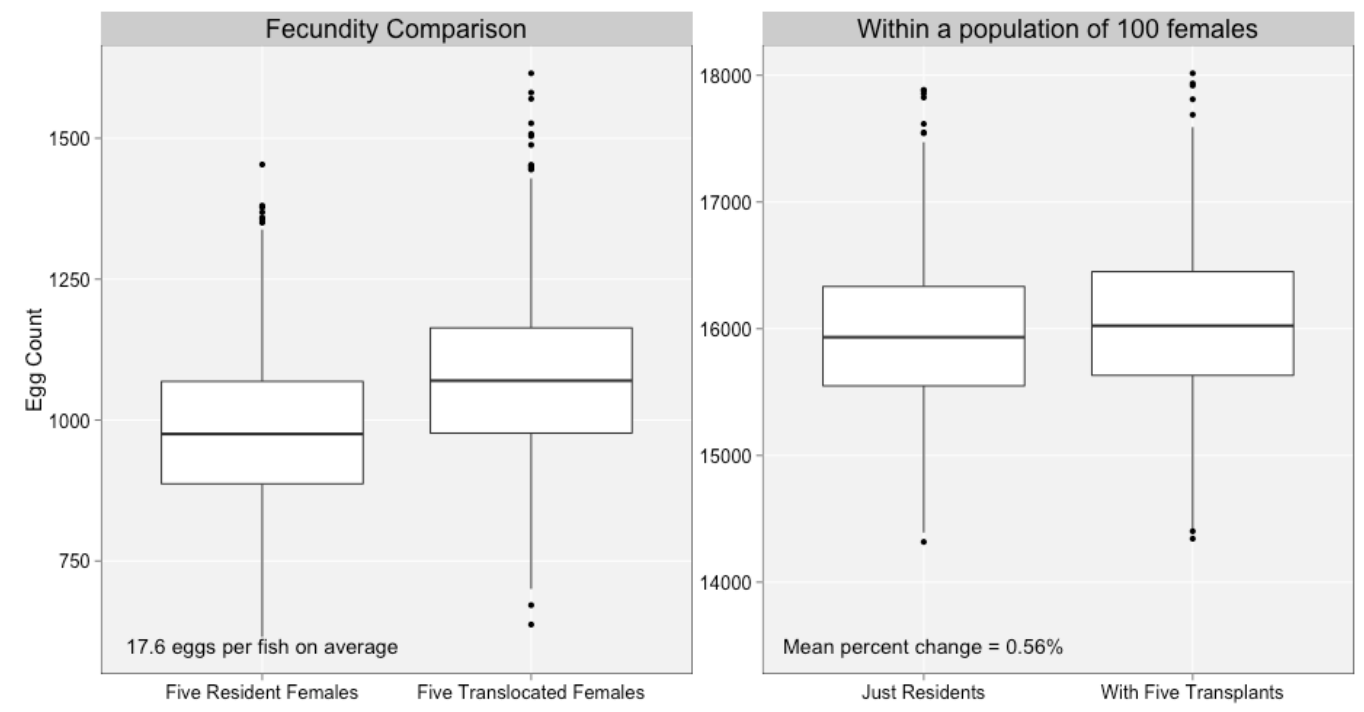

Figure 9. Comparison of fecundity of simulated female brook trout with observed transplantresident body size difference. The left panel contains a box plot of 1000 replicates of total fecundity of five simulated female brook trout by using the size-fecundity relationship from Letcher et al. (2007). The mean body size was $190 \mathrm{~mm}$ and $200 \mathrm{~mm}$ for resident and transplants respectively with a standard deviation of 30 . The second panel demonstrates the relative effect of five transplants on overall fecundity of hypothetical population of 100 females with a range of body sizes from $100-300 \mathrm{~mm}$. The simulated translocated brook trout on average had 17.6 more eggs per female, and produced half a percent increase in a hypothetical population of 100 females on average. (note: This is under the assumption that translocated brook trout was larger than residents, an assumption that lacks substantial statistical support). 


\section{BIBLIOGRAPHY}

Allendorf FW, Phelps SR (1981) Use of Allelic Frequencies to Describe Population-Structure. Canadian Journal of Fisheries and Aquatic Sciences, 38, 1507-1514.

Allendorf FW, Luikart G, eds (2007) Conservation and the genetics of populations Blackwell Publishing., Malden, MA; Oxford.

Almudevar A (2007) A graphical approach to relatedness inference. Theoretical population biology, 71, 213-229.

Anderson EC, Dunham KK (2008) The influence of family groups on inferences made with the program Structure. Molecular Ecology Resources, 8, 1219-1229.

Annett B, Gerlach G, King TL, Whiteley AR (2012) Conservation Genetics of Remnant Coastal Brook Trout Populations at the Southern Limit of Their Distribution: Population Structure and Effects of Stocking. Transactions of the American Fisheries Society, 141, 1399-1410.

Araki H, Waples RS, Ardren WR, Cooper B, Blouin MS (2007) Effective population size of steelhead trout: influence of variance in reproductive success, hatchery programs, and genetic compensation between life-history forms. Molecular ecology, 16, 953-966.

Berejikian BA, Tezak EP, LaRae AL (2000) Female mate choice and spawning behaviour of Chinook salmon under experimental conditions. Journal of fish biology, 57, 647-661.

Burnham KP, Anderson DR (2002) Model selection and multimodel inference a practical information-theoretic approach. 
Coombs JA, Letcher BH, Nislow KH (2010) PedAgree: Software to quantify error and assess accuracy and congruence for genetically reconstructed pedigree relationships. Conservation Genetics Resources, 2, 147-150.

Coombs JA (2010) Reproduction in the wild: the effect of individual life history strategies on population dynamics and persistence. Dissertation, University of Massachusetts.

Dunham JB, Vinyard GL, Rieman BE (1997) Habitat Fragmentation and Extinction Risk of Lahontan Cutthroat Trout. North American Journal of Fisheries Management, 17, 1126-1133.

Dunham J, Baxter C, Fausch K, et al (2008) Evolution, Ecology, and Conservation of Dolly Varden, White-spotted Char, and Bull Trout. Fisheries, 33, 537-550.

Edmands S (2007) Between a rock and a hard place: evaluating the relative risks of inbreeding and outbreeding for conservation and management. Molecular Ecology, 16, 463-475.

Evanno G, Regnaut S, Goudet J (2005) Detecting the number of clusters of individuals using the software structure: a simulation study. Molecular Ecology, 14, 2611-2620.

Fausch K, Rieman B, Dunham J, Young M, Peterson D (2009) Invasion versus isolation: tradeoffs in managing native salmonids with barriers to upstream movement. Conservation biology : the journal of the Society for Conservation Biology, 23, 859-70.

Francis RM (2014) pophelper: An R package for analysis of STRUCTURE and TESS files.

Frankham R (2015) Genetic rescue of small inbred populations: meta-analysis reveals large and consistent benefits of gene flow. Molecular Ecology, . 
Frankham R, Ballou JD, Eldridge MDB, et al (2011) Predicting the Probability of Outbreeding Depression. Conservation Biology, 25, 465-475.

Fraser DJ (2008) How well can captive breeding programs conserve biodiversity? A review of salmonids. Evolutionary Applications, 1, 535-586.

Gaudemar Bd, Beall E (1998) Effects of overripening on spawning behaviour and reproductive success of Atlantic salmon females spawning in a controlled flow channel. Journal of fish biology, 53, 434-446.

Gemmell NJ, Metcalf VJ, Allendorf FW (2004) Mother's curse: the effect of mtDNA on individual fitness and population viability. Trends in Ecology \& Evolution, 19, 238-244.

Goudet J (2014) hierfstat: Estimation and tests of hierarchical F-statistics.

Harig AL, Fausch KD (2002) Minimum habitat requirements for establishing translocated cutthroat trout populations. Ecological Applications, 12, 535-551.

Hudy M, Downey DM, Bowman DW (2000) Successful Restoration of an Acidified Native Brook Trout Stream through Mitigation with Limestone Sand. North American Journal of Fisheries Management, 20, 453-466.

Hudy M, Coombs JA, Nislow KH, Letcher BH (2010) Dispersal and Within-Stream Spatial Population Structure of Brook Trout Revealed by Pedigree Reconstruction Analysis. Transactions of the American Fisheries Society., 139, 1276. 
Hudy M, Thieling TM, Gillespie N, Smith EP (2008) Distribution, Status, and Land Use Characteristics of Subwatersheds within the Native Range of Brook Trout in the Eastern United States. North American journal of fisheries management., 28, 1069.

Hudy M, Thieling TM, Gillespie N, Smith EP (2008) Distribution, status, and land use characteristics of subwatersheds within the native range of brook trout in the Eastern United States. North American Journal of Fisheries Management, 28, 1069-1085.

Hughes N (1992) Ranking of Feeding Positions by Drift-Feeding Arctic Grayling (ThymallusArcticus) in Dominance Hierarchies. Canadian Journal of Fisheries and Aquatic Sciences, 49, 1994-1998.

Kanno Y, Letcher BH, Hitt NP, Boughton DA, Wofford JEB, Zipkin EF (2015) Seasonal weather patterns drive population vital rates and persistence in a stream fish. Global Change Biology, , n/a-n/a.

King TL, Lubinski BA, Burnham-Curtis MK, Stott W, Morgan,R.P.,II (2012) Tools for the management and conservation of genetic diversity in brook trout (Salvelinus fontinalis): tri- and tetranucleotide microsatellite markers for the assessment of genetic diversity, phylogeography, and historical demographics. Conservation Genetics Resources, 4, 539-543.

King T, Eackles M, Letcher B (2005) Microsatellite DNA markers for the study of Atlantic salmon (Salmo salar) kinship, population structure, and mixed-fishery analyses. Molecular Ecology Notes, 5, 130-132. 
Koizumi I (2011) Integration of ecology, demography and genetics to reveal population structure and persistence: a mini review and case study of stream-dwelling Dolly Varden. EFF Ecology of Freshwater Fish, 20, 352-363.

Lande R (1993) Risks of Population Extinction from Demographic and Environmental Stochasticity and Random Catastrophes. American Naturalist, 142, 911-927.

Letcher BH, Nislow KH, Coombs JA, O'Donnell MJ, Dubreuil TL, Svensson E (2007) Population Response to Habitat Fragmentation in a Stream-Dwelling Brook Trout Population. PLoS ONE PLOS ONE, 2, e1139.

Letcher BH, Coombs JA, Nislow KH (2011) Maintenance of phenotypic variation: repeatability, heritability and size-dependent processes in a wild brook trout population. Evolutionary Applications, 4, 602-615.

Madsen T, Shine R, Olsson M, Wittzell H (1999) Conservation biology - Restoration of an inbred adder population. Nature, 402, 34-35.

Miller JM, Poissant J, Hogg JT, Coltman DW (2012) Genomic consequences of genetic rescue in an insular population of bighorn sheep (Ovis canadensis). Molecular ecology, 21, 1583-1596.

Naish K, Seamons T, Dauer M, Hauser L, Quinn T (2013) Relationship between effective population size, inbreeding and adult fitness-related traits in a steelhead (Oncorhynchus mykiss) population released in the wild. Molecular ecology, 22, 1295-309.

Newman D, Tallmon D (2001) Experimental evidence for beneficial fitness effects of gene flow in recently isolated populations. Conservation Biology, 15, 1054-1063. 
Newman D, Pilson D (1997) Increased Probability of Extinction Due to Decreased Genetic Effective Population Size: Experimental Populations of Clarkia pulchella. Evolution, 51, 354362.

Nislow KH, Armstrong JD (2012) Towards a life-history-based management framework for the effects of flow on juvenile salmonids in streams and rivers. Fisheries Management and Ecology, 19, 451-463.

Otis DL, Burnham KP, White GC, Anderson DR (1978) Statistical Inference from Capture Data on Closed Animal Populations. wildmono Wildlife Monographs, , 3-135.

Palomares F, Lopez-Bao JV, Rodriguez A, et al (2012) Possible Extinction Vortex for a Population of Iberian Lynx on the Verge of Extirpation. Conserv.Biol.Conservation Biology, 26, 689-697.

Peacock MM, Dochtermann NA (2012) Evolutionary potential but not extinction risk of Lahontan cutthroat trout (Oncorhynchus clarkii henshawi) is associated with stream characteristics. Canadian Journal of Fisheries and Aquatic Sciences, 69, 615-626.

Peterson DP, Rieman BE, Dunham JB, Fausch KD, Young MK (2008) Analysis of trade-offs between threats of invasion by nonnative brook trout (Salvelinus fontinalis) and intentional isolation for native westslope cutthroat trout (Oncorhynchus clarkii lewisi). Can.J.Fish.Aquat.Sci.Canadian Journal of Fisheries and Aquatic Sciences, 65, 557-573. Pielou EC (1975) Ecological diversity Wiley New York. 
Pritchard JK, Stephens M, and Donnelly P (2000) Inference of Population Structure Using Multilocus Genotype Data. Genetics, 155.

Rice WR (1989) Analyzing Tables of Statistical Tests. Evolution, 43, 223-225.

Rodriguez-Ramilo ST, Wang J (2012) The effect of close relatives on unsupervised Bayesian clustering algorithms in population genetic structure analysis. Molecular Ecology Resources, 12, 873-884.

Roghair CN, Dolloff CA (2005) Brook Trout Movement during and after Recolonization of a Naturally Defaunated Stream Reach. North American Journal of Fisheries Management, 25, 777784.

Rouseset F (2008) GENEPOP'007: a complete re-implementation of the genepop software for Windows and Linux. Molecular Ecology Resources, 8, 103-106.

Slate J, Pemberton JM (2007) Admixture and patterns of linkage disequilibrium in a free-living vertebrate population. Journal of Evolutionary Biology, 20, 1415-1427.

Tallmon DA, Luikart G, Waples RS (2004) The alluring simplicity and complex reality of genetic rescue. Trends in ecology \& evolution., 19, 489-496.

Tetzlaff D, Soulsby C, Youngson A, et al (2005) Variability in stream discharge and temperature: a preliminary assessment of the implications for juvenile and spawning Atlantic salmon. Hydrology and Earth System Sciences Discussions, 9, 193-208.

Trumbo BA, Nislow KH, Stallings J, et al (2014) Ranking Site Vulnerability to Increasing Temperatures in Southern Appalachian Brook Trout Streams in Virginia: An Exposure- 
Sensitivity Approach. Transactions of the American Fisheries Society Transactions of the American Fisheries Society, 143, 173-187.

VDGIF (Virginia Department of Game and Inland Fisheries) (2014) 2014 Catchable Trout Stocking Plan. http://www.dgif.virginia.gov/fishing/trout/catchable-trout-stocking-plan.pdf.

Venables WN, Ripley BD (2002) Modern Applied Statistics with S.

Wang J (2004) Sibship reconstruction from genetic data with typing errors. Genetics, 166, 19631979.

Waples RS, England PR (2011) Estimating contemporary effective population size on the basis of linkage disequilibrium in the face of migration. Genetics, 189, 633-44.

Waples RS, Antao T, Luikart G (2014) Effects of Overlapping Generations on Linkage Disequilibrium Estimates of Effective Population Size. Genetics, 197, 769-780.

Waples RS, Do C (2010) Linkage disequilibrium estimates of contemporary N-e using highly variable genetic markers: a largely untapped resource for applied conservation and evolution. Evolutionary Applications, 3, 244-262.

Waples RS, Do C (2008) LDNE: a program for estimating effective population size from data on linkage disequilibrium. Molecular Ecology Resources, 8, 753-756.

Weeks AR, Sgro CM, Young AG, et al (2011) Assessing the benefits and risks of translocations in changing environments: a genetic perspective. Evolutionary Applications, 4, 709-725. 
Wenger S, Isaak D, Luce C, et al (2011) Flow regime, temperature, and biotic interactions drive differential declines of trout species under climate change. Proceedings of the National Academy of Sciences of the United States of America, 108, 14175-80.

Westemeier R, Brawn J, Simpson S, et al (1998) Tracking the long-term decline and recovery of an isolated population. Science, 282, 1695-1698.

White SL, Gowan C (2013) Brook trout use individual recognition and transitive inference to determine social rank. Behavioral Ecology, 24, 63-69.

Whiteley AR, Hudy M, Robinson ZL, Coombs JA, Nislow KH (2014) Patch-based metrics: A cost effective method for $<$ br $/>$ short- and long-term monitoring of EBTJV wild Brook Trout populations? Wild Trout Symposium, Wild Trout XI: Looking back and moving forward.

Whiteley AR, Coombs JA, Hudy M, et al (2013) Fragmentation and patch size shape genetic structure of brook trout populations. Can.J.Fish.Aquat.Sci.Canadian Journal of Fisheries and Aquatic Sciences, 70, 678-688.

Whiteley AR, Coombs JA, Hudy M, Robinson Z, Nislow KH, Letcher BH (2012) Sampling strategies for estimating brook trout effective population size.(Report). Conservation Genetics, 13.

Whiteley AR, Fitzpatrick SW, Funk WC, Tallmon DA (2015) Genetic rescue to the rescue. Trends in Ecology \& Evolution, 30, 42-49. 
Whiteley AR, Wenburg JK, Wenburg JK, Frissell CA, Martin JC, Allendorf FW (2010) Genetic variation and effective population size in isolated populations of coastal cutthroat trout. Conservation Genetics, 11, 1929-1943.

Winter DJ (2012) mmod: an R library for the calculation of population differentiation statistics. Molecular Ecology Resources, 12, 1158-1160.

Xu CL, Letcher BH, Nislow KH (2010) Size-dependent survival of brook trout Salvelinus fontinalis in summer: effects of water temperature and stream flow. Journal of fish biology, 76, 2342-2369. 